\title{
Poaceae da Estação Ecológica do Seridó, Rio Grande do Norte, Brasil
}

\author{
Caroline Gracielle Torres Ferreira ${ }^{1,4}$, Regina Célia de Oliveira ${ }^{1}$, José Francisco Montenegro Valls ${ }^{2}$ e \\ Maria Iracema Bezerra de Loiola ${ }^{3}$
}

Recebido: 27.11.2008; aceito: 13.11.2009

ABSTRACT - (Poaceae in the "Seridó" Ecological Station, Rio Grande do Norte, Brazil). This is the first floristic survey of grass species undertaken in Rio Grande do Norte. The family has great economic and ecological value. In the Seridó area, where the "caatinga vegetation" is open and shows a continuous herbaceous stratum, representatives of the family constitute the main component of the vegetation in the raining season. We documented the occurrence of 57 species of Poaceae, distributed in 34 genera, in the Seridó Ecological Station. Of those species, 41 are native to the area and 16 are exotic. The paper includes analytical keys for the grass tribes genera and species descriptions, a discussion about the delimitation of some species, the distribution of the species in the Station, and botanical illustrations. Eragrostis cilianensis (Bellardi) Vignolo ex Janch., Mesosetum annuum Swallen and Cenchrus ciliaris L. are recorded for the first time for the Flora of Rio Grande do Norte.

Key words: Caatinga, Gramineae, herbaceous plants

RESUMO - (Poaceae da Estação Ecológica do Seridó, Rio Grande do Norte, Brasil). Trata-se do primeiro levantamento florístico das espécies de Poaceae da Estação Ecológica do Seridó. A família apresenta grande valor econômico e ecológico. A região denominada Seridó apresenta uma Caatinga aberta com estrato herbáceo contínuo, onde os representantes da família constituem um dos principais componentes, principalmente na estação chuvosa. Foi registrada a ocorrência de 57 espécies distribuídas em 34 gêneros, das quais 41 são nativas e 16 exóticas. $O$ trabalho consta de chaves analíticas para tribos, gêneros e espécies, descrições, discussão sobre a delimitação de algumas espécies, distribuição dos táxons na Estação e ilustrações botânicas. Eragrostis cilianensis (Bellardi) Vignolo ex Janch., Mesosetum annuum Swallen e Cenchrus ciliaris L. são citadas pela primeira vez para o Rio Grande do Norte.

Palavras-chave: Caatinga, Gramíneas, plantas herbáceas

\section{Introdução}

A Caatinga abrange uma área de aproximadamente $800.000 \mathrm{~km}^{2}$, que se estende pelos Estados do Piauí, Maranhão, Ceará, Rio Grande do Norte, Paraíba, Pernambuco, Alagoas, Sergipe, Bahia e norte de Minas Gerais (IBGE 2004). Caracteriza-se por apresentar pluviosidade baixa (350-700 $\mathrm{mm}$ por ano), potencial de evapotranspiração elevado (2.000 mm anuais) e insolação de 2.800 h/ano (Hargreaves 1974) e uma grande variação fisionômica, principalmente quanto à densidade e ao porte das plantas (Amorim et al.2005).

Apesar de ser o único bioma exclusivamente brasileiro, a Caatinga é um dos menos conhecidos na América do Sul do ponto de vista cientifico (MMA 1998). Somam-se à insuficiência de conhecimento cientifico, a degradação ambiental que hoje atinge mais de $60 \%$ da área do bioma, aliada ao número reduzido de unidades de conservação (Tabarelli et al. 2000).

O Seridó encontra-se na Depressão Sertaneja Setentrional, uma das oito ecorregiões da Caatinga e das mais impactadas (Velloso et al. 2002). Esta ecorregião compartilha com a Depressão Sertaneja Meridional a paisagem mais típica do semi-árido nordestino: uma extensa planície baixa, de relevo predominantemente suave-ondulado, com elevações residuais disseminadas na paisagem. O termo Seridó designa não apenas uma região geográfica, mas o tipo de Caatinga que predomina na área: aberta, com grandes extensões de plantas herbáceas e solos que tendem a ser mais rasos que no resto da ecorregião

1. Universidade Federal Rural do Semi-Árido, Herbário MOSS, Setor de Fitossanidade, BR-110, km 45, Caixa Postal 137, 59625-900 Mossoró, RN, Brasil

2. Embrapa Recursos Genéticos e Biotecnologia, Parque Estação Biológica, Av. W5 Norte (final), Caixa Postal 02372, 70770-900 Brasília, DF, Brasil

3. Universidade Federal do Ceará, Departamento de Biologia, B1. 906 Campus do Pici, 60455-970 Fortaleza, CE, Brasil

4. Autor para correspondência: caroline-torres@hotmail.com 
e muito suscetíveis à erosão (Velloso et al. 2002). Constitui um dos quatro núcleos de desertificação do Brasil, provocada pelo homem ou por deficiências ambientais naturais (Sampaio et al. 2003).

A família Poaceae engloba cerca de 10.000 espécies amplamente distribuídas nas regiões tropicais e subtropicais do planeta, sendo predominantes na maioria das formações campestres (Clayton \& Renvoize 1986). Apresenta grande valor econômico, com muitas espécies forrageiras, invasoras, utilizadas na alimentação humana (cana-de-açúcar e cereais), na construção civil e artesanato (bambus, taquaras) e na cobertura do solo, inclusive para recuperação de áreas degradadas.

O conhecimento sobre as Poaceae do Nordeste é incipiente. Destacam-se os trabalhos de Renvoize (1984) que ilustrou e descreveu aproximadamente 300 espécies da Bahia, Nascimento \& Renvoize (2001), que listaram as espécies de Poaceae forrageiras do Piauí e Maranhão, Tenório (1968) que estudou as Poaceae do município de Recife (PE), Oliveira et al. (2003) que estudaram o gênero Ichnanthus P. Beauv. na Chapada da Diamantina, Silva \& Maciel (2007) que trataram dos gêneros Sporobolus R. Br. e Leptochloa P. Beauv. em Pernambuco.

O presente trabalho objetivou contribuir para o conhecimento e identificação das espécies de Poaceae no Estado do Rio Grande do Norte, especialmente na Estação Ecológica do Seridó e fornecer informações adicionais provenientes de observações em campo.

\section{Material e métodos}

A Estação Ecológica do Seridó (ESEC) localizase no município de Serra Negra do Norte, no sudoeste do Estado do Rio Grande do Norte, entre as coordenadas $6^{\circ} 34^{\prime} 00^{\prime \prime}-6^{\circ} 37^{\prime} 00^{\prime \prime} \mathrm{S}$ e $37^{\circ} 15^{\prime}$ $37^{\circ} 16$ '00"W, perfazendo 1.166,38 hectares (Camacho $\&$ Baptista 2005).

A área da ESEC está inserida no complexo cristalino, com predominância de solos do tipo Luvissolos Crômicos (EMBRAPA 1999). Estes apresentam profundidade variando de pouco profunda a rasa, horizonte $\mathrm{B}$ textural, elevado teor de nutrientes, valor de saturação de bases próximo a $80 \%$ e relevo suave a fortemente ondulado. Também ocorrem Neossolos Litólicos e Vertissolos (Santana \& Souto 2006).

Pela classificação de Köppen, o clima é BsWh, ou seja, seco, muito quente e com estação chuvosa no verão (MMA 2004). De acordo com a estação metereológica instalada na ESEC, no período de novembro 2005 a outubro 2006 a temperatura média anual foi de $34,48{ }^{\circ} \mathrm{C}$, a temperatura mínima anual $21,97{ }^{\circ} \mathrm{C}$ e a umidade relativa do ar (UR) média $60,7 \%$. As chuvas concentraram-se entre fevereiro e maio e a pluviosidade total foi de $836,1 \mathrm{~mm}$ anual.

Com relação à vegetação da ESEC, Camacho \& Batista (2005) verificaram diferenças estruturais segundo classes de altitude. A vegetação que ocupa as cotas altitudinais entre $200-250 \mathrm{~m}$ foi classificada como arbustiva embora ocorram pequenos campos, sendo esta a mais representativa na ESEC. Esse setor ocupa o início da encosta da Serra Verde, sendo recoberto por solos vérticos (que ficam encharcados na época das chuvas e fendilhados na seca). A 220 $\mathrm{m}$ de altitude, em relevo plano e cobertura arbustiva, ocorre a maior diversidade de espécies lenhosas. Nas altitudes de $350 \mathrm{~m}$, encontra-se a Caatinga arbórea. A 385 m de altitude, encontra-se a Caatinga arbóreoarbustiva. Nessa cota altitudinal, com afloramentos rochosos, encontra-se um dos pontos referenciais de coleta, conhecido na região por "Mirante".

Vale destacar ainda que próximo à Sede da ESEC, em altitudes próximas a $200 \mathrm{~m}$, há um grande açude, com restos de culturas em seu entorno, principalmente de capineiras. Já o local denominado "Lajedo dos Tanques" é uma área de afloramento rochoso com cavidades profundas, permanentemente repletas de água. E, finalmente, a "Lagoa do Junco" é um lago periódico e natural, rico em macrófitas. Destaca-se que em todos esses ambientes, as gramíneas estão presentes.

Para a obtenção das amostras botânicas foram percorridas as trilhas existentes na ESEC em todos os ambientes acima citados, totalizando 12 expedições mensais entre janeiro de 2006 e abril de 2007.

As identificações foram feitas por comparação e através de literatura especializada. Foram consultadas coleções pertencentes aos Herbários MOSS, UFRN, IPA e EAC, cujas siglas constam em Holmgren et al. (2005). Os espécimes foram incorporados ao Herbário MOSS e as duplicatas distribuídas a alguns herbários nacionais, incluindo a coleção didática da ESEC.

As descrições foram baseadas em amostras frescas e herborizadas, assim como em observações de campo.

As chaves de tribo e gênero assim como os termos utilizados nas descrições, foram baseadas em Longhi-Wagner et al. (2001), que oferece um glossário esclarecedor das eventuais dúvidas no texto. 


\section{Resultados e Discussão}

Embora trabalhos relacionados à vegetação do Seridó citem apenas uma ou duas espécies de Poaceae para a região (Andrade-Lima 1981, Camacho \& Batista 2005), foram encontrados no presente estudo, 57 espécies, distribuídas em 34 gêneros, sete tribos e quatro subfamílias de Poaceae. Deste total, 41 espécies são nativas $(71,9 \%)$ e 16 exóticas $(28,1 \%)$.

A subfamília Panicoideae é a mais bem representada na área, com 19 gêneros e 32 espécies dessas, 23 são nativas $(71,9 \%)$ e nove exóticas $(28,1 \%)$. Dentre as Chloridoideae, foram registradas a ocorrência de 13 gêneros e 21 espécies, das quais, 14 espécies são nativas $(66,7 \%)$ e sete exóticas $(33,3 \%)$. Aristidoideae está representada por um gênero e três espécies nativas e a subfamília Ehrhartoideae por uma única espécie nativa. Para a definição das tribos de Chloridoideae, seguiu-se Longhi-Wagner et al. (2001), já que não há uma filogenia robusta para essa subfamília (Hilu \& Alice 2001).

O fato da área da ESEC ter sido uma fazenda antes da sua fundação em 1982, explica o alto número de espécies de Poaceae exóticas, muitas das quais tradicionalmente cultivadas como forragem.

Amorim et al. (2005) comentaram que a flora da ESEC tem um número de espécies arbustivo-arbóreas menor que os das áreas de Caatinga pesquisadas em outras regiões. No entanto, ao contrário de outros autores, acreditam que a pressão antrópica não é a causa exclusiva do baixo número de espécies, relacionando a escassez ao efeito da disponibilidade hídrica. Quanto à estrutura, é um tipo de caatinga distinto dos demais por apresentar vegetação mais aberta, baixa e com menor biomassa de espécies lenhosas que outras áreas de caatinga. Os dados da literatura são deficientes em análises do estrato herbáceo.

Amorin et al. (2005) encontraram 15 espécies lenhosas na ESEC e Santana \& Souto (2006) 22. Portanto, Poaceae está representada por mais que o dobro do número de espécies lenhosas, o que mostra a importância da família na área estudada. Araújo et al. (2005) comentaram que a flora herbácea é mais rica que a lenhosa e é pouco conhecida na Caatinga; esses autores encontraram 62 espécies herbáceas em microhabitats de Caatinga em Caruaru, PE. Nesse estudo, as Poaceae estão representadas por apenas sete espécies, três das quais exóticas à flora local.

Andrade-Lima (1981) e Camacho \& Batista (2005) citaram apenas Aristida setifolia Kunth para a região do Seridó. Andrade-Lima (1981) ressaltou que a escassez de representantes de Poaceae na Caatinga poderia estar associada ao pastejo intensivo. De fato, coletas efetuadas no entorno da ESEC, que está fortemente pastejado, tem demonstrado um número mais restrito de espécies, com abundância das ruderais e pioneiras e deficiência daquelas nativas de maior palatabilidade.

Nas áreas antropizadas da ESEC ocorrem, abundantemente, espécies pioneiras e invasoras: Aristida adscensionis L., A. setifolia, Cenchrus ciliaris L., Chloris barbata Sw., C. virgata Sw., Dactyloctenium aegyptium (L.) Willd., Digitaria bicornis (Lam.) Roem. \& Schult., Eleusine indica (L.) Gaertn., Enteropogon mollis (Nees) Clayton, Paspalum melanospermum Desv. ex Poir., P. scutatum Nees ex Trin., Tragus berteronianus Schult., Urochloa fusca (Sw.) B.F. Hansen \& Wunderlin, U. mollis (Sw.) Morrone \& Zuloaga e U. plantaginea (Link) R.D. Webster.

Algumas espécies exóticas estão restritas ao entorno do açude artificial da ESEC, como Echinochloa polystachya (Kunth) Hitchc., Eragrostis cilianensis e Urochloa mutica (Forssk.) T.Q. Nguyen. As espécies nativas Hymenachne amplexicaulis (Rudge) Nees e Paspalidium geminatum (Forssk.) Stapf. também têm distribuição restrita às margens do açude e, curiosamente, Eragrostis hypnoides (Lam.) Britton, Sterns \& Poggenb. e Reimarochloa brasiliensis (Spreng.) Hitchc. vegetam apenas no período seco, tendo sido observadas somente no mês de janeiro, nos locais de "retração" da lâmina de água.

$\mathrm{Na}$ área estudada há espécies de distribuição restrita, demonstrando diferenças entre as comunidades herbáceas. Aristida elliptica (Nees) Kunth, Steirachne diandra Ekman, Leptochloa panicea subsp. brachiata (Steud.) N.W. Snow e Paspalum clavuliferum C. Wright foram encontradas preferencialmente nos Vertissolos. Próximo ao "Lajedo dos Tanques" e nos pequenos "campos" junto da via principal da ESEC, há extensões de Mesosetum pappophorum (Nees) Kuhlm. e M. annuum Swallen as quais, aparentemente, não cohabitam. Heteropogon melanocarpus (Elliott) Benth. e Tripogon spicatus (Nees) Ekman foram localizadas apenas nas proximidades do Mirante, em ambiente rupestre. Uma única população de Luziola brasiliensis (Trin.) Pilg. foi encontrada nas cavidades das rochas com acúmulo permanente de água no "Lajedo dos Tanques".

Este estudo constatou que a vegetação herbácea do Seridó é rica em espécies de Poaceae, ocorrendo 41 espécies nativas, o que amplia significativamente 
o número anteriormente citado na literatura (Andrade-Lima 1981, Camacho \& Batista 2005). As fitofisionomias da ESEC são diferentes entre si, no que se refere à composição do estrato herbáceo, pois as espécies de Poaceae não se distribuem uniformemente na área. Para a melhor compreensão das diferenças florísticas entre as formações savânicas da ESEC, estudos quantitativos são desejáveis.

Apresenta-se, a seguir, chave de identificação de tribos, gêneros e espécies de Poaceae de ocorrência confirmada na Estação Ecológica do Seridó, descrições e ilustrações de caracteres diagnósticos.

Chave de tribos de Poaceae da ESEC

1. Glumas rudimentares ou nulas; estames (1)6(9); espiguetas 1-floras; flores unissexuadas masculinas e femininas no mesmo indivíduo

1. Glumas, ao menos a gluma superior, desenvolvidas; estames (1-)3; espiguetas 1-floras a plurifloras; flores bissexuadas.

2. Cariopse com epicarpo e mesocarpo deliqüescente em contato com a umidade, liberando a semente envolta pelo endocarpo, que às vezes é viscoso

II. Zoyseae

2. Cariopse com epicarpo, mesocarpo e endocarpo secos, indeiscente, mesmo em contato com a umidade, completamente unido à testa da semente em toda sua superfície

3. Espiguetas dispostas aos pares em cada nó da ráquis, uma séssil e uma pedicelada, geralmente caindo em conjunto com o entrenó da ráquis frágil; antécios hialinos

III. Andropogoneae

3. Espiguetas isoladas ou raramente binadas ou em grupos, todas pediceladas, caindo isoladamente ou com articulação na base do ramo espiciforme da panícula; antécios pigmentados

4. Espiguetas mesótonas ou basítonas, 1-plurifloras, com ou sem antécios apicais rudimentares

5. Espiguetas com 1 antécio IV. Aristideae

5. Espiguetas com 2 a numerosos antécios

6. Panícula típica V. Eragrostideae

6. Panícula de ramos unilaterais espiciformes VI. Cynodonteae

4. Espiguetas acrótonas, bifloras, geralmente o antécio superior bissexual e o inferior masculino ou neutro VII. Paniceae

\section{Oryzeae}

Representada na ESEC por uma espécie do gênero Luziola.

Luziola A.L. Juss.

Panícula típica, laxa. Espiguetas solitárias, pediceladas; articulação na base do antécio; flores unissexuadas, monóicas, 1-floras, sem antécios apicais rudimentares; glumas ausentes; estames 6-9; antécios pigmentados. Cariopse com epicarpo, mesocarpo e endocarpo livres e coriáceos.

Clayton \& Renvoize (1989) citam 11 espécies para o gênero, que se distribui do sul dos Estados Unidos até a Argentina. Está representado na ESEC por uma espécie.
Luziola brasiliensis (Trin.) Pilg., Nat. Pflanzenfam. (ed. 2) 14 d: 157. 1956.

Figura $2 \mathrm{~g}, \mathrm{~h}$

Plantas anuais, ca. $60 \mathrm{~cm}$ alt. Lâminas foliares planas, concentradas na base da planta, $11-18 \times 0,3-0,7$ $\mathrm{cm}$. Inflorescências terminais e axilares, parcialmente inclusas na folhagem. Espiguetas masculinas com antécios alvacentos quando jovens e palhetes na maturidade, mais longas que as femininas.

Material examinado: BRASIL. Rio GrandE do NorTE: Serra Negra do Norte, Estação Ecológica do Seridó, Lajedo dos Tanques, 24-VI-2006, C.G.T. Ferreira \& G.S. Araújo 226 (MOSS); idem, 21-IV-2007, R.C.Oliveira et al. 1900 (MOSS). 
Coletada com flores e frutos em abril e junho. Encontrada em água empoçada em cavidades de formações rochosas.

\section{Zoyseae}

Representada na ESEC por uma espécie de Sporobolus.

\section{Sporobolus R. Br.}

Panícula típica, laxa ou contraída. Espiguetas solitárias, pediceladas, basítonas, articulação acima das glumas, que permanecem na inflorescência após a queda dos antécios maduros; flores bissexuadas, 1-floras, sem antécios apicais rudimentares; glumas desenvolvidas; estames 3. Cariopse com epicarpo e mesocarpo deliqüiescente em contato com a umidade, liberando a semente envolta pelo endocarpo, que às vezes é viscoso.

Gênero com cerca de 100 espécies distribuídas nas regiões tropicais, subtropicais e temperadas do mundo. No Brasil ocorrem 27 espécies e três variedades (Boechat et al. 2001). Está representado na ESEC por uma espécie.

Sporobolus pyramidatus (Lam.) Hitchc., Man. Grasses W. Ind.: 84. 1936.

\section{Figura 31}

Planta perene, cespitosa, ca. $32 \mathrm{~cm}$ alt., com folhas concentradas na base da planta. Panículas com dimorfismo, as jovens contraídas e as maduras piramidais, muito ramificada, os ramos proximais verticilados e abertos na maturidade. Gluma inferior atingindo a metade do comprimento do lema e a superior igual ou subigual ao lema.

Material examinado: BRASIL. Rio GRANDE Do NoRTE: Serra Negra do Norte, Estação Ecológica do Seridó, Estrada - próximo alojamento, 20-V-2006, R.C. Oliveira \& C.G.T. Ferreira 1668 (MOSS).

Coletada com flores e frutos em maio. Encontrada em solos arenosos antropizados.

\section{Andropogoneae}

Andropogoneae está representada na ESEC por três gêneros e três espécies.

Sorghum arundinaceum (Desv.) Stapf (figura 3 k) foi introduzida por cultivo e, por isso, não será descrita.

Chave para gêneros de Andropogoneae da ESEC

1. Panícula laxa Sorghum

1. Panícula com ramos unilaterais espiciformes
2. Ramo unilateral espiciforme da panícula solitário e não subtendidos por uma espatéola; espigueta séssil com arista longa de $10-15 \mathrm{~cm}$ compr.

\section{Heteropogon}

2. Ramos unilaterais espiciformes da panícula em número de 2 ou 3 subtendidos e parcialmente inclusos numa espatéola evidente; espigueta séssil com arista curta de $0,4-1,1 \mathrm{~cm}$ compr.

Andropogon

\section{Andropogon L.}

Panícula com 2 ou 3 ramos espiciformes por espatéola; um par de espiguetas em cada nó da ráquis, heterógamas, uma séssil e uma pedicelada, caindo em conjunto com o entrenó da ráquis na maturação. Espigueta séssil com calo piloso, com 2 antécios hialinos, 1-floras, bissexuais, acrótonas; glumas desenvolvidas, com arista de 0,4-1,1 cm compr.; antécio inferior neutro, lema mútico; antécio superior com flor bissexuada, lema de ápice 2-dentado e aristado; espiguetas pediceladas neutras ou com flor masculina, múticas ou aristuladas. Estames 3. Cariopse típica.

Gênero com cerca de 100 espécies, distribuídas especialmente nos trópicos (Clayton \& Renvoize 1989). Zanin \& Longhi-Wagner (2006) relacionaram a ocorrência de 28 espécies de Andropogon para o Brasil. Está representado na ESEC por uma espécie.

Andropogon angustatus (J. Presl) Steud., Syn. Pl. Glumac. 1: 370. 1854.

Figura 1 a

Plantas anuais, cespitosas, com folhas distribuídas ao longo do colmo. Panícula com ramos espiciformes subentendidos e parcialmente inclusos numa espatéola evidente. Espigueta séssil com gluma inferior de 4,5 mm compr., sem glândulas no dorso.

Material selecionado: BRASIL. Rio GRANDE Do NorTe: Serra Negra do Norte, Estação Ecológica do Seridó, Estrada para o Mirante, 23-VI-2006, C.G.T. Ferreira \& G.S. Araújo 20 (MOSS); próximo a Lagoa do Junco, 2-VIII-2006, C.G.T. Ferreira \& M.L.Silva 276 (MOSS).

Coletada com flores e frutos de abril a agosto. Encontrada em margem de estrada, local arenopedregoso, em formação rochosa, serra, vertissolo e campo aberto. 


\section{Heteropogon Pers.}

Inflorescência com 1 ramo espiciforme, não subtendido por espatéola; um par de espiguetas em cada nó da ráquis, homógamas, uma séssil e uma pedicelada, caindo em conjunto com o entrenó da ráquis na maturação. Espigueta séssil com 2 antécios hialinos, bissexuais, 1-flora, acrótonas; glumas desenvolvidas; antécio inferior neutro, lema mútico; antécio superior com flor bissexuada, lema de ápice inteiro e aristado; espiguetas pediceladas neutras ou com flor masculina, aristadas. Estames 3. Cariopse típica.

Gênero com seis espécies tropicais e subtropicais (Clayton \& Renvoize 1989). São citadas para o Brasil as duas espécies que ocorrem em praticamente toda a região Neotropical (Filgueiras 2009). Está representado na ESEC por uma espécie.

Heteropogon melanocarpus (Elliott) Benth., J. Linn. Soc., Bot. 19(115-116): 71. 1881.

Figura $2 b$

Plantas anuais, cespitosas, com folhas distribuídas ao longo do colmo. Panícula com um ramo espiciforme não subtendido por uma espatéola evidente. Espigueta séssil com gluma inferior ca. $20 \mathrm{~mm}$ compr., com glândulas no dorso.

Material examinado: BRASIL. Rio GRANDE do NoRTE: Serra Negra do Norte, Estação Ecológica do Seridó, $50 \mathrm{~m}$ antes do Mirante, 23-VI-2006, C.G.T. Ferreira \& G.S. Araújo 188 (MOSS).

Coletada com flores e frutos em junho. Encontrada em locais pedregosos em serra.

\section{Aristideae}

Representada por um gênero e duas espécies.

\section{Aristida L.}

Panícula típica, laxa ou espiciforme. Espiguetas solitárias, pediceladas, basítonas, com articulação acima das glumas, que permanecem na inflorescência após a queda dos antécios maduros; flores bissexuadas, 1-flora, sem antécios apicais rudimentares; glumas desenvolvidas; lemas com aristas tripartidas. Estames 3. Cariopse típica.

Aproximadamente 250 espécies tropicais e subtropicais (Clayton \& Renvoize 1989). No Brasil está representado por 38 espécies (Longhi-Wagner 1993). Está representado na ESEC por três espécies.
Chave para espécies de Aristida da ESEC

1. Plantas sem ramificação nos nós superiores; panícula oblonga, congesta, (1-)1,8-5 cm compr. .......... A. elliptica

1. Plantas ramificadas nos nós superiores; panícula aberta, efusa (8-) $15-30 \mathrm{~cm}$ compr.

2. Lema com coluna de 2,5-6 $\mathrm{mm}$ de compr., cilíndrico, com nódulo de articulação com a arista no ápice da coluna A. setifolia

2. Lema sem coluna, comprimido lateralmente, sem nódulo de articulação com a arista ...... A. adscensionis

Aristida adscensionis L., Sp. Pl. 1: 82. 1753.

Figura $1 \mathrm{c}$

Planta anual, ramificada nos nós superiores. Panícula semi-contraída ou aberta, (8-)15-30 cm compr. Lema com compressão lateral, com margens convolutas não formando um sulco longitudinal ventral, arista sem coluna e sem nódulo de articulação com a arista.

Material selecionado: BRASIL. Rio GRAnde Do NoRTE: Serra Negra do Norte, Estação Ecológica do Seridó, Estrada para o Mirante, 23-VI-2006, C.G.T. Ferreira \& G.S. Araújo 194 (MOSS).

Coletada com flores e frutos de janeiro a agosto. Encontrada em margem de estrada, local arenopedregoso, vertissolo e campo aberto.

Andrade-Lima (1981) citou a ocorrência de $A$. setifolia Kunth no Seridó e Camacho \& Batista (2005), citaram a espécie para a ESEC.

O hábito de A. adscencionis é semelhante ao de A. setifolia, ambas geralmente ramificam-se nos nós superiores. Essas espécies são diferenciadas pela arista com coluna articulada e lema cilíndrico em $A$. setifolia e coluna e articulação ausentes e lema com compressão lateral em A. adscencionis (LonghiWagner 1993).

Aristida elliptica (Nees) Kunth, Enum. Pl. 1: 93. 1833.

Figura $1 \mathrm{~d}$

Planta anual, sem ramificação nos nós superiores. Panícula congesta, (1-)1,8-5 cm compr. Lema sem compressão lateral, margens involutas formando um sulco longitudinal ventral, sem coluna e sem nódulo de articulação com a arista. 
Material selecionado: BRASIL. Rio Grande Do NoRTE: Serra Negra do Norte, Estação Ecológica do Seridó, Vertissolo, 24-I-2006, R.C. Oliveira et al. 1616 (MOSS); entrada para estrada, a partir do Mirante, 3-VIII-2006, C.G.T. Ferreira et al. 287 (MOSS).

Coletada com flores e frutos de abril a agosto. Encontrada em margem de estrada, local arenopedregoso, vertissolo e campo aberto.

Aristida elliptica possui distribuição preferencial nos vertissolos, onde forma populações densas e contínuas, com inflorescências persistentes na planta na época da seca, tornando-as conspícuas nesse período.

Aristida setifolia Kunth in Humb., Bonpl. \& Kunth, Nov. gen. sp. 1: 122.1816.

Planta anual, com ramificação nos nós superiores. Panícula semi-contraída ou aberta de lema cilíndrico, com margens convolutas não formando um sulco longitudinal ventral, arista com coluna de 2,5-6 mm compr., com nódulo de articulação com a arista no ápice da coluna.

Material selecionado: BRASIL. Rio GRANDE Do NorTE: Serra Negra do Norte, Estação Ecológica do Seridó, 100 m após a entrada da Estação, 20-V-2006, R.C. Oliveira \& C.G.T. Ferreira 1621 (MOSS); estrada, 24-VI-2006, C.G.T. Ferreira \& G.S. Araújo 261 (MOSS);

Há confusão nas identificações de A. adscensionis e A. setifolia. A presença de coluna com nó de articulação no ápice é um caráter constante em $A$. setifolia. É freqüente a ocorrência de espécimes cujo lema é recoberto por máculas escuras, tornando-o conspícuo entre as glumas esverdeadas.

\section{Eragrostideae}

Representada na ESEC por dois gêneros e sete espécies.

\section{Chave para espécies de Eragrostideae da ESEC}

1. Lemas aristulados Steirachne diandra

1. Lemas múticos

2. Plantas estoloníferas Eragrostis hypnoides

2. Plantas cespitosas ou decumbentes.

3. Páleas com cílios de base tuberculada nas quilhas, evidentes a olho nu.

4. Panículas espiciformes, densifloras; espiguetas mais longas que o pedicelo; estames 2 Eragrostis ciliaris

4. Panículas abertas, laxifloras; espiguetas mais curtas que o pedicelo; estames 3

Eragrostis tenella

3. Páleas com cílios sem base tuberculada nas quilhas, não evidentes a olho nu.

5. Ápice dos lemas estreitado abruptamente, agudo e reflexo; espiguetas com lemas que se desarticulam e páleas persistentes Eragrostis maypurensis

5. Ápice dos lemas obtuso, subagudo a agudo, não reflexo; espiguetas com lema e pálea que se desarticulam.

6. Plantas sem glândulas; ráquila tenaz e totalmente aparente; espiguetas lineares Eragrostis pilosa

6. Plantas com anel glandular sob os nós e glândulas nas glumas, lemas e páleas das espiguetas; ráquila frágil e não aparente; espiguetas largamente ovais ...... Eragrostis cilianensis

\section{Eragrostis Wolf}

Panículas típica, laxas ou contraídas. Espiguetas solitárias, basítonas, pediceladas, com articulação acima ou abaixo das glumas; flores bissexuadas, plurifloras, com ou sem antécios apicais rudimentares; glumas desenvolvidas; lemas múticos, pigmentados. Estames 2-3. Cariopse típica.
Gênero cosmopolita com cerca de 350 espécies, 51 das quais ocorrem no Brasil (Boechat \& Longhi-Wagner 2001). Está representado na ESEC por seis espécies.

Eragrostis cilianensis (Bellardi) Vignolo ex Janch., Mitt. Naturwiss. Vereins. Univ. Wien 5: 110. 1907. Figura $1 \mathrm{q}$ 
Plantas cespitosas, com um anel glandular sob os nós. Panícula densiflora. Espiguetas largamente ovais, mais longas que os pedicelos, com glândulas nas glumas, lema e pálea; ráquila não aparente, desarticulando-se entre os antécios, glumas temporariamente persistentes; antécios densamente imbricados, ápice mucronado, não reflexo; páleas com cílios nos $2 / 3$ superiores, não visíveis a olho nu, caducas. Estames 3.

Material examinado: BRASIL. Rio GRANDE do Norte: Serra Negra do Norte, Estação Ecológica do Seridó, Margem açude, 11-IV-2006, C.G.T. Ferreira 21 (MOSS); idem, 20-V-2006, R.C. Oliveira \& C.G.T. Ferreira 1666 (MOSS); idem, 3-VIII-2006, C.G.T. Ferreira et al. 290 (MOSS).

Coletada com flores e frutos de abril a agosto. Encontrada na margem do açude.

Nativa da Europa, tendo sido registrada, no Brasil, para os Estados da Bahia, Minas Gerais, Pernambuco e Rio Grande do Sul (Boechat \& Longhi-Wagner 2001). Trata-se, portanto, do primeiro registro de ocorrência no Rio Grande do Norte.

Eragrostis ciliaris (L.) R. Br. in Tuckey, Narr. Exped. Zaire: 478. 1818.

Figura $1 \mathrm{r}$

Plantas cespitosas, não glandulosas. Panículas densifloras. Espiguetas elípticas, não glandulosas, mais longas que os pedicelos; ráquila aparente, desarticulando-se entre os antécios; antécios densamente imbricados, ápice agudo ou acuminado, não reflexo; páleas com cílios visíveis a olho nu, caducas. Estames 2.

Material examinado: BRASIL. Rio GRANDE Do NoRTE: Serra Negra do Norte, Estação Ecológica do Seridó, Vertissolo,23-VI-2006, C.G.T.Ferreira \& G.S.Araújo 216 (MOSS); estrada para o Lajedo dos Tanques, 24VI-2006, C.G.T.Ferreira \& G.S. Araújo 237 (MOSS); sem local, 5-VII-2005, R. Pereira \& C. Ferreira 3019 (MOSS).

Coletada com flores e frutos em junho e julho. Encontrada em vertissolo e solo arenoso. Espécie naturalizada, pioneira.

Eragrostis hypnoides (Lam.) Britton, Sterns \& Poggenb., Prelim. Cat.: 69. 1888.

Figura $1 \mathrm{~s}$
Plantas estoloníferas, não glandulosas. Panículas densifloras. Espiguetas lanceoladas ou lineares, mais longas que os pedicelos, não glandulosas; ráquila tenaz, não aparente, espiguetas persistindo inteiras, quando maduras; antécios densamente imbricados, ápice agudo ou acuminado, não reflexo; páleas com cílios não visíveis a olho nu, persistentes. Estames 2.

Material examinado: BRASIL. Rio GRANDE do NoRTE: Serra Negra do Norte, Estação Ecológica do Seridó, Margem do açude, 24-I-2006, R.C. Oliveira et al. 1612 (MOSS); idem, 24-I-2006 R.C. Oliveira et al. 1613 (MOSS).

Coletada com flores e frutos em janeiro. Encontrada na margem de açude no período seco.

Eragrostis hypnoides é uma espécie muito característica, pelos colmos estoloníferos prostrados e inflorescências mais conspícuas que a porção vegetativa, que possui folhas menores que $1,5 \mathrm{~cm}$ comprimento.

Eragrostis maypurensis (Kunth) Steud., Syn. Pl. Glumac. 1: 276. 1854.

Figura $1 \mathrm{t}, \mathrm{u}$

Plantas cespitosas, não glandulosas. Panículas densifloras. Espiguetas largamente elípticas, mais longas que os pedicelos, não glandulosas; ráquila tenaz, não aparente, lemas desarticulando-se da base para o ápice, páleas persistentes; antécios densamente imbricados; lemas com ápice estreitado abruptamente, agudo e reflexo para fora; páleas sem cílios. Estames 2.

Material selecionado: BRASIL. Rio GRANDE Do NoRTE: Serra Negra do Norte, Estação Ecológica do Seridó, Estrada para Lagoa do Junco, 2-VIII-2006, C.G.T. Ferreira \& M.L. Silva 273 (MOSS); idem, 20IV-2007, R.C. Oliveira et al. 1891 (MOSS).

Coletada com flores e frutos de abril a agosto. Encontrada em locais arenosos, sendo observada também em campos abertos, formando grandes populações.

Boechat \& Longhi-Wagner (2001) e Boechat et al. (2001) destacaram como caráter o colo da bainha foliar com uma linha de tricomas só interrompida na nervura central em E. maypurensis. O caráter não é constante para os espécimens da ESEC. O ápice do lema só se torna reflexo, quando as espiguetas estão totalmente desenvolvidas. A distinção pela cariopse tampouco é segura, já que a marca negra em semiarco pode ou não estar presente em E. maypurensis (Boechat 2001). Assim, a distinção desta espécie de 
E. rufescens Schrad. ex Schult. não é muito clara e há possibilidade de que ambas ocorram na área.

Eragrostis pilosa (L.) P. Beauv., Ess. Agrostogr. 71, $162,175.1812$.

Figura $1 \mathrm{v}$

Plantas cespitosas, não glandulosas. Panículas laxas. Espiguetas elípticas, iguais ou mais curtas que os pedicelos não glandulosos; ráquila tenaz, totalmente aparente, lemas e páleas caducos da base para o ápice, restando apenas a ráquila flexuosa; antécios laxamente imbricados, ápice agudo, não reflexo; páleas com cílios não visíveis a olho nu. Estames 3 .

Material examinado: BRASIL. Rio GRANDE do NoRTE: Serra Negra do Norte, Estação Ecológica do Seridó, Margem do açude, 24-X-2006, C.G.T. Ferreira 298 (MOSS); trilha da caveira, 12-IV-2006, C.G.T. Ferreira 71 (MOSS).

Coletada com flores e frutos de março a junho. Encontrada em locais areno-pedregosos, vertissolos e locais úmidos.

Eragrostis tenella L., Sp. pl.: 69. 1753.

Figura $1 \mathrm{w}$

Plantas cespitosas, não glandulosas. Panículas laxas. Espiguetas elípticas, tão longas quanto ou mais curtas que os pedicelos não glandulosos; ráquila frágil, aparente, desarticulando-se entre os antécios caducos ou só a pálea do antécio inferior persistente; antécios densamente imbricados, ápice obtuso, não reflexo; páleas com cílios visíveis a olho nu. Estames 3.

Material selecionado: BRASIL. RIo GRANDE Do NoRTE: Serra Negra do Norte, Estação Ecológica do Seridó, Margem do açude, 11-IV-2006, C.G.T. Ferreira 22 (MOSS); em frente ao alojamento, 24-VI-2006, C.G.T. Ferreira \& G.S. Araújo 246 (MOSS).

Coletada com flores e frutos de abril a junho. Encontrada em locais antropizados.
Espécie naturalizada, pioneira e freqüente.

O nome Eragrostis amabilis (L.) Wight \& Arn. é mais difundido. Comentários sobre a sinonimização a E. tenella podem ser obtidos em Peterson \& Boechat (2009).

\section{Steirachne Ekman}

Panículas típicas, laxas ou contraídas. Espiguetas solitárias, basítonas, pediceladas, com articulação acima das glumas, plurifloras, flores bissexuadas, com ou sem antécios apicais rudimentares; glumas desenvolvidas; lemas aristulados, pigmentados. Estames 2. Cariopse típica.

Gênero com duas espécies do Brasil e Guianas (Renvoize 1986). Está representado na ESEC por uma espécie.

Steirachne diandra Ekman, Ark. Bot. 10(17): 36, t. 5, f. 1, t. 6, f. 17, text f. 1-2. 1911.

Figura $3 \mathrm{~m}$

Plantas cespitosas, não glandulosas. Panículas laxas. Espiguetas lineares, mais longas que os pedicelos não glandulosos; ráquila frágil, aparente, desarticulando-se entre os antécios caducos; antécios laxamente imbricados, ápice aristulado, não reflexo; páleas escabras. Estames 2. Cariopse típica.

Material selecionado: BRASIL. Rio GRAnde Do NorTE: Serra Negra do Norte, Estação Ecológica do Seridó, Estrada para Lagoa do Junco, 2-VIII-2006, C.G.T.Ferreira \& M.L. Silva 272 (MOSS); sem local, 3-VIII-2006, C.G.T. Ferreira et al. 286 (MOSS).

Coletada com flores e frutos de junho a agosto. Encontrada em locais arenosos antropizados e em campos abertos formando grandes populações.

\section{Cynodonteae}

Representada na ESEC por nove gêneros e 13 espécies.

Chave para gêneros de Cynodonteae da ESEC

1. Espiguetas em fascículos; gluma superior com cerdas espinescentes sobre as nervuras Tragus

1. Espiguetas solitárias ou pareadas; gluma superior sem cerdas espinescentes sobre as nervuras

2. Panícula com um ramo unilateral espiciforme Tripogon

2. Panícula típica ou com vários ramos unilaterais espiciformes

3. Lemas com aristas tripartidas Bouteloua

3. Lema com arista inteira ou mútico 
4. Panículas apenas com espiguetas de primeira ordem, as quais possuem pedicelos duas vezes mais longos que o comprimento da espigueta ..... Neesiochloa

4. Panícula com ramos unilaterais espiciformes com pedicelos mais curtos que o comprimento da espigueta, subsésseis ou sésseis

5. Panícula com os ramos alternos ao longo do colmo florífero Leptochloa

5. Panícula com ramos concentrados no ápice do colmo florífero, conjugados, digitados, verticilados ou subverticilados

6. Ráquis terminada em uma extensão aguda e estéril; gluma superior com ápice truncado e aristado Dactyloctenium

6. Ráquis com espiguetas até o ápice, sem extensão aguda e estéril; gluma com ápice superior agudo ou acuminado, mútico ou com arista curta

7. Plantas estoloníferas Cynodon

7. Plantas cespitosas ou decumbentes

8. Lemas múticos Eleusine

8. Lemas aristados

9. Espiguetas com 2 antécios estéreis; lema com compressão lateral; arista com 6-7 mm compr.; antécios estéreis sem calo piloso Chloris

9. Espiguetas com 1 antécio estéril; lema com compressão dorsal; arista com 4-5 mm compr.; antécios estéreis com calo piloso ...... Enteropogon

\section{Bouteloua Lag.}

Plantas cespitosas ou decumbentes. Panículas com 4-20 ramos espiciformes sem uma extensão apical estéril desprovida de espiguetas. Espiguetas sésseis ou subsésseis, solitárias, basítonas, plurifloras, com um antécio bissexual e um ou dois estéreis, sem calo piloso; articulação na base do ramo espiciforme da inflorescência; glumas desenvolvidas, acuminadas ou com arista terminal, sem cerdas espinescentes ao longo das nervuras; lemas com compressão dorsal, com aristas tripartidas de 4-6 mm compr., antécios pigmentados. Estames 3. Cariopse típica.

Gênero com cerca de 40 espécies distribuídas do Canadá até a Argentina, quatro das quais ocorrem no Brasil (Boechat et al. 1993). Está representado na ESEC por duas espécies.

\section{Chave para espécies de Bouteloua da ESEC}

1. Espiguetas 3-11 por ramo da inflorescência; glumas semelhantes entre si, a inferior pouco menor que a superior B. americana

1. Espiguetas 2-4 por ramo da inflorescência; glumas desiguais, a inferior conspícuamente menor que a superior B. aristidoides

Bouteloua americana (L.) Scribn., Proc. Acad. Nat. Sci. Philadelphia 43(2): 306. 1891.

Figura $1 \mathrm{e}$
Plantas anuais. Panícula com ramos geralmente dispostos bilateralmente ao longo do colmo florífero, 5-12 ramos por inflorescência, 3-11 espiguetas por ramo. Espiguetas homomórficas, constituídas de um antécio basal bissexual e outro geralmente reduzido ao lema ou atrofiado, triaristado.

Material examinado: BRASIL. RIo GRANDE do NoRTE: Serra Negra do Norte, Estação Ecológica do Seridó, ca. $200 \mathrm{~m}$ após açude, 20-V-2006, R.C. Oliveira \& C.G.T.Ferreira 1652 (MOSS); ao lado do alojamento, 3-VIII-2006, C.G.T. Ferreira et al. 293 (MOSS).

Coletada com flores e frutos de abril a agosto. Encontrada em margem de estrada, local arenopedregoso, serra, vertissolo e campo aberto.

Boechat et al. (1993) comentaram que $B$. americana é perene e destacaram o aspecto frequiente de planta anual. Todo o material observado na ESEC parece anual. Beetle (1987) relatou que plantas depauperadas dessa espécie podem ter $8 \mathrm{~cm}$ compr., mas que as "normais" atingem $1 \mathrm{~m}$ alt. Todo o material analisado da ESEC não ultrapassa $50 \mathrm{~cm}$ altura.

Bouteloua aristidoides (Kunth) Griseb., Fl. Brit. W. I.: 537. 1864.

Figura $1 \mathrm{f}$

Plantas anuais. Panícula com ramos geralmente dispostos unilateralmente ao longo do colmo florífero, 4-15(-20) ramos por inflorescência, 2-4 espiguetas por ramo. Espiguetas heteromórficas, as proximais com 


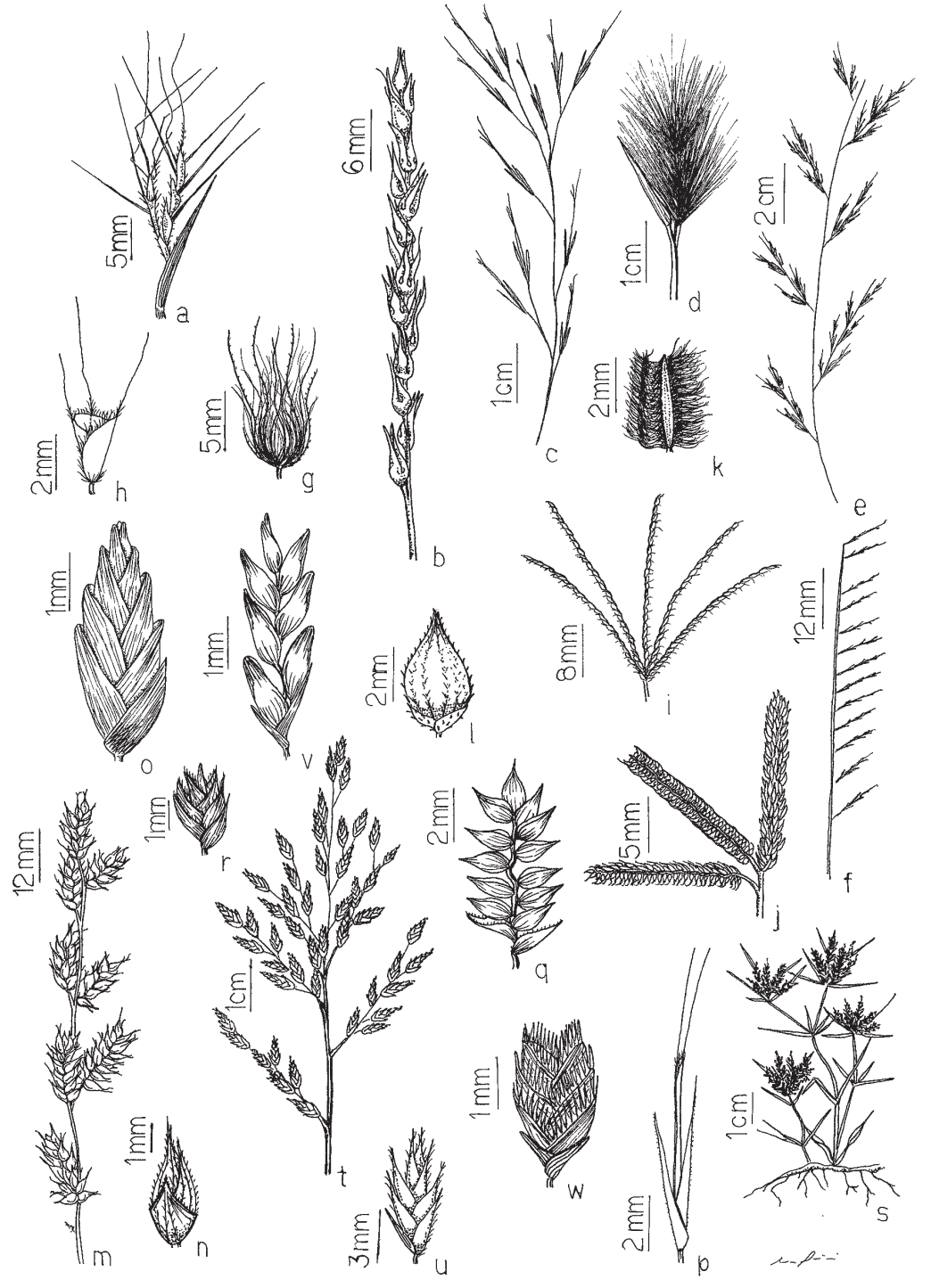

Figura 1. Espécies de Poaceae da Estação Ecológica do Seridó, RN, Brasil. a. Andropogon angustatus, ramos da inflorescência. b. Anthephora hermaphrodita, inflorescência. c. Aristida adscensionis, inflorescência. d. A. elliptica, inflorescência. e. Bouteloua americana, inflorescência. f. B. aristidoides, inflorescência. g. Cenchrus ciliaris, invólucro de cerdas. h. Chloris barbata, antécios inferiores. i. Cynodon dactylon, inflorescência. j. Dactyloctenium aegyptium, inflorescência. k. Digitaria bicornis, espigueta. 1. Echinochloa colona, espigueta. m-n. Echinochloa polystachya. m. inflorescência. n. espigueta. o. Eleusine indica, espigueta. p. Enteropogon mollis, espigueta. q. Eragrostis cilianensis, espigueta. r. E. ciliaris, espigueta. s. E. hypnoides, hábito. t-u. E. maypurensis. t. inflorescência. u. espigueta. v. E. pilosa, espigueta. w. E. tenella, espigueta. (a: Ferreira \& Silva 276; b: Ferreira \& Silva 278; c: Ferreira \& Araújo 261; d: Ferreira et al. 287; e: Ferreira et al. 293; f: Ferreira \& Araújo 247; g: Ferreira \& Oliveira 3; h: Ferreira \& Oliveira Irmão 37B; i: Ferreira 297; j: Ferreira et al. 289; k: Ferreira \& Silva 271; 1: Ferreira \& Araújo 222; m-n: Ferreira 306; o: Ferreira \& Araújo 241; p: Ferreira \& Araújo 262; q: Ferreira et al. 290; r: Ferreira \& Araújo 216; s: Oliveira et al. 1613; t-u: Ferreira \& Silva 273; v: Ferreira 298; w: Ferreira \& Araújo 246)

Figure 1. Species of Poaceae from the "Seridó" Ecological Station, Rio Grande do Norte, Brazil. a. Andropogon angustatus, branches of inflorescence; b. Anthephora hermaphrodita, inflorescence; c. Aristida adscensionis, inflorescence; d. A. elliptica, inflorescence; e. Bouteloua americana, inflorescence; f. B. aristidoides, inflorescence; g. Cenchrus ciliaris, involucre of bristles; h. Chloris barbata, lower florets; i. Cynodon dactylon, inflorescence; j. Dactyloctenium aegyptium, inflorescence; k. Digitaria bicornis, spikelet; 1. Echinochloa colona, spikelet; m-n. E. polystachya. m. inflorescence. n. spikelet; o. Eleusine indica, spikelet; p. Enteropogon mollis, spikelet; q. Eragrostis cilianensis, spikelet; r. E. ciliaris, spikelet; s. E. hypnoides, habit; t-u. E. maypurensis. t. inflorescence. u. spikelet; v. E. pilosa, spikelet; w. E. tenella, spikelet. (a: Ferreira \& Silva 276; b: Ferreira \& Silva 278; c: Ferreira \& Araújo 261; d: Ferreira et al. 287; e: Ferreira et al. 293; f: Ferreira \& Araújo 247; g: Ferreira \& Oliveira 3; h: Ferreira \& Oliveira Irmão 37B; i: Ferreira 297; j: Ferreira et al. 289; k: Ferreira \& Silva 271; 1: Ferreira \& Araújo 222; m-n: Ferreira 306; o: Ferreira \& Araújo 241; p: Ferreira \& Araújo 262; q: Ferreira et al. 290; r: Ferreira \& Araújo 216; s: Oliveira et al. 1613; t-u: Ferreira \& Silva 273; v: Ferreira 298; w: Ferreira \& Araújo 246). 
um antécio bissexual; as distais constituídas de um antécio bissexual e um reduzido ao lema triaristado.

Material selecionado: BRASIL. Rio GRAnde Do Norte: Serra Negra do Norte, Estação Ecológica do Seridó, Em frente ao alojamento, 27-III-2004, M.I.B. Loiola et al. 834 (MOSS, UFRN); idem, 24-VI-2006, C.G.T. Ferreira \& G.S. Araújo 247 (MOSS).

Coletada com flores e frutos de março a junho. Encontrada em margem de estrada e local arenopedregoso.

\section{Chloris Sw.}

Plantas cespitosas. Panícula com 6-16 ramos unilaterais espiciformes verticilados no ápice do colmo florífero sem uma pequena extensão apical estéril e desprovida de espiguetas. Espiguetas sésseis ou subsésseis, solitárias, basítonas, antécio inferior com flor bissexual, acompanhado de 2 antécios apicais neutros reduzidos ao lema, antécios estéreis sem calo piloso, com articulação acima das glumas, que permanecem na inflorescência após a queda dos antécios maduros; glumas agudas ou acuminadas, múticas, sem cerdas espinescentes sobre as nervuras; lema com compressão lateral; aristas com 6-7 mm compr., antécios pigmentados. Estames 3. Cariopse típica.

Segundo Longhi-Wagner (2001) o gênero é constituído por cerca de 40 espécies tropicais e subtropicais. Está representado na ESEC por duas espécies.

\section{Chave para espécies de Chloris da ESEC}

1. Plantas anuais; espiguetas $3-3,5 \mathrm{~mm}$ compr. C. virgata

1. Plantas perenes; espiguetas $2-2,2 \mathrm{~mm}$ compr. C. barbata

Chloris barbata Sw., Fl. Ind. Occid. 1: 200. 1797.

Figura $1 \mathrm{~h}$

Plantas perenes. Espiguetas 2-2,2 mm compr., com 3 antécios aristados, lema inferior com arista de 3-5 mm compr.

Material examinado: BRASIL. Rio GRANDE Do NoRTE: Serra Negra do Norte, Estação Ecológica do Seridó, Estrada principal, 11-IV-2006, C.G.T. Ferreira \& V.A.O. Irmão 37b (MOSS).
Coletada com flores e frutos em abril. Encontrada em solo arenoso antropizado.

Chloris virgata Sw., Fl. Ind. Occid. 1: 203. 1797.

Plantas anuais.Espiguetas 3-3,5 mm compr., (2-)3 antécios, dois dos quais aristados, lema inferior com arista de 5-15 mm compr.

Material selecionado: BRASIL. Rio GRANDE Do NoRTE: Serra Negra do Norte, Estação Ecológica do Seridó, Em frente ao alojamento, XI-2005, M.I.B. Loiola et al. 836 (MOSS, UFRN); estrada, ca. 100 $\mathrm{m}$ do portão principal, 20-V-2006, R.C. Oliveira \& C.G.T. Ferreira 1632 (MOSS).

Coletada com flores e frutos de março a junho. Encontrada em solos arenosos e antropizados.

\section{Cynodon Rich.}

Plantas estoloníferas. Panícula com (3-)4-5(-6) ramos unilaterais espiciformes verticilados no ápice do colmo florífero, sem extensão apical estéril e desprovida de espiguetas. Pedicelos mais curtos que o comprimento das espiguetas. Espiguetas solitárias, basítonas, antécio inferior com flor bissexual, acompanhados ou não de 1 antécio apical rudimentar, antécios estéreis sem calo piloso, com articulação acima das glumas, que permanecem na inflorescência após a queda dos antécios maduros; glumas agudas ou acuminadas, múticas, sem cerdas espinescentes sobre as nervuras; antécios pigmentados; lema com compressão lateral, mútico. Estames 3. Cariopse típica.

Cerca de oito espécies dos trópicos e subtrópicos (Longhi-Wagner 2001). Está representado na ESEC por uma espécie.

Cynodon dactylon (L.) Pers., Syn. Pl. 1: 85. 1805.

Figura $1 \mathrm{i}$

Plantas estolonífero-rizomatosas com prefoliação conduplicada. Panícula com ramos espiciformes de $3,2 \mathrm{~cm}$ compr. Espiguetas de (2,0-)2,3-2,5 mm compr.

Material examinado: BRASIL. Rio GrandE do NorTE: Serra Negra do Norte, Estação Ecológica do Seridó, Margem do açude, 24-X-2006, C.G.T. Ferreira 297 (MOSS).

Coletada com flores e frutos o ano todo. Encontrada em locais úmidos, sendo observada também em locais areno-pedregosos.

Cosmopolita, ocorrendo em ambientes alterados (Longhi-Wagner 2001). 
Está representada pela variedade típica, $C$. dactylon var. dactylon, caracterizada por LonghiWagner (2001) pelas lâminas foliares glabras ou escabras.

\section{Dactyloctenium Willd.}

Plantas cespitosas, decumbentes ou estoloníferas. Panícula com (2-)3-5 ramos unilaterais espiciformes verticilados no ápice do colmo florífero com uma pequena extensão apical estéril e desprovida de espiguetas. Espiguetas sésseis, solitárias, basítonas, antécio inferior com flor bissexual, com ou sem antécio apical rudimentar, com articulação acima das glumas, que permanecem na inflorescência após a queda dos antécios maduros; gluma inferior mútica, a superior truncada e aristada, sem cerdas espinescentes sobre as nervuras; antécios pigmentados; lema com compressão lateral, acuminado ou mucronado. Estames 3. Cariopse típica.

Gênero com 13 espécies predominantemente africanas e indianas, uma das quais introduzida e amplamente distribuída na América tropical e subtropical (Boechat et al. 2001).

Dactyloctenium aegyptium (L.) Willd., Enum. pl.: 1029. 1809.

\section{Figura $1 \mathrm{j}$}

Plantas cespitosas, decumbentes ou estoloníferas. Panículas com ramos unilaterais rígidos. Espiguetas 3-4-floras, 3,2-4,5 mm compr., densamente agrupadas sobre a ráquis; lemas acuminados ou mucronados com quilhas conspícuas, 2,0-4,0(-4,1) mm compr.

Material selecionado: BRASIL. Rio Grande do NoRTE: Serra Negra do Norte, Estação Ecológica do Seridó, Próximo ao alojamento, 12-IV-2006, C.G.T. Ferreira 72 (MOSS); estrada para alojamento, 3-VIII2006, C.G.T. Ferreira et al. 289 (MOSS).

Encontrada com flores e frutos de abril a outubro. Coletada em margem de estrada, em locais arenopedregosos e no vertissolo.

\section{Eleusine Gaertn.}

Plantas cespitosas. Panícula com 3-11 ramos unilaterais espiciformes verticilados ou digitados no ápice do colmo florífero, sem extensão apical estéril desprovida de espiguetas. Pedicelos mais curtos que a espigueta. Espiguetas solitárias, basítonas, antécio inferior com flor bissexuada, sem antécio apical rudimentar, com articulação acima das glumas, que permanecem na inflorescência após a queda dos antécios maduros; glumas agudas ou acuminadas, múticas, sem cerdas espinescentes sobre as nervuras; antécios pigmentados; lema com compressão lateral, mútico. Estames 3. Cariopse típica.

Sete a nove espécies de regiões tropicais (LonghiWagner 2001). Está representado na ESEC por uma espécie.

Eleusine indica (L.) Gaertn., Fruct. sem. O1. 1: 8.1788 .

Figura 10.

Plantas cespitosas. Panícula com ramos unilaterais espiciformes flexíveis. Espiguetas 3-7 floras, densamente agrupadas sobre a ráquis em duas séries; glumas quilhadas; lemas agudos.

Material selecionado: BRASIL. Rio GRANDE do NorTE: Serra Negra do Norte, Estação Ecológica do Seridó, Próximo ao alojamento, 12-IV-2006, C.G.T. Ferreira \& V.A.O. Irmão 69 (MOSS); idem, 24-VI2006, C.G.T. Ferreira \& G.S. Araújo 241 (MOSS).

Encontrada com flores e frutos de abril a agosto. Coletada em margem de estrada, em locais arenopedregosos.

Espécie pioneira naturalizada.

\section{Enteropogon Nees}

Plantas cespitosas. Panícula com 5-9 ramos unilaterais espiciformes subverticilados no ápice do colmo florífero, sem extensão apical estéril e desprovida de espiguetas. Pedicelo mais curto que o comprimento da espigueta. Espiguetas solitárias, basítonas; antécio inferior com flores bissexuadas e um antécio apical neutro ou reduzido com calo piloso; articulação acima das glumas, que persistem na inflorescência após a queda dos antécios maduros; glumas minutamente bidentadas no ápice, com ou sem arista, sem cerdas espinescentes sobre as nervuras; antécios pigmentados; lema com compressão dorsal, aristas 4-5 mm compr. Estames 3. Cariopse típica.

Segundo Clayton \& Renvoize (1989), Enteropogon possui 17 espécies de regiões tropicais. Está representado na ESEC por uma espécie.

Clayton \& Renvoize (1989) comentam a dificuldade de distinguir o gênero Enteropogon de Chloris, ressaltando os caracteres forma do lema e cariopse com pericarpo "livre". No material 
examinado não foram encontradas cariopses com pericarpo livre. No material da ESEC, as cariopses de Enteropogon são muito mais longas (3-3,5 mm compr.) do que as de Chloris (1-1,5 mm compr.) e com aspecto cimbiforme, ou seja, com a superfície dorsal côncava e a ventral convexa. As cariopses de Chloris possuem a superfície dorsal côncava e a ventral plana. Os ramos espiciformes da inflorescência de Enteropogon são sinuosos e mais longos (6,5-13 cm compr.). Os ramos das inflorescências de Chloris são rígidos e curtos (3-8 cm compr.).

Enteropogon mollis (Nees) Clayton, Kew Bull. 37: 419. 1982.

Figura $1 \mathrm{p}$

Planta anual, 30-110 cm de altura. Inflorescência com ramos de 6,5-13 cm compr. Espiguetas com lemas esparsamente ciliados. Cariopse 3-3,5 mm compr., cimbiforme.

Material selecionado: BRASIL. Rio GRANDE DO NORTE: Serra Negra do Norte, Estação Ecológica do Seridó, $50 \mathrm{~m}$ antes do Mirante, 23-VI-2006, C.G.T. Ferreira \& G.S. Araújo 190 (MOSS); estrada principal, 24-VI2006, C.G.T. Ferreira \& G.S. Araújo 262 (MOSS).

Coletada com flores e frutos de maio a junho. Encontrada em margem de estrada, locais arenopedregoso.

\section{Leptochloa P. Beauv.}

Plantas cespitosas. Panícula com vários ramos unilaterais espiciformes alternos ao longo do eixo, sem extensão apical estéril. Pedicelos mais curtos que o comprimento da espigueta. Espiguetas solitárias, basítonas; antécios com flor bissexuada, 2-floras a plurifloras, com ou sem antécio apical neutro ou reduzido ao lema; antécios estéreis sem calo piloso; articulação acima das glumas, que permanecem na inflorescência após a queda dos antécios maduros; glumas agudas ou acuminadas, múticas, sem cerdas espinescentes sobre as nervuras; antécios pigmentados, lema com compressão lateral com arístulas_de 0,3-0,6 $\mathrm{mm}$ compr. Estames 3. Cariopse típica.

Composto por, aproximadamente, 40 espécies nas regiões tropicais e subtemperadas do mundo (Clayton \& Renvoize 1989). Para o Brasil, Costa-eSilva \& Maciel (2007), referem-se à ocorrência de seis a oito espécies. Está representado na ESEC por duas espécies.
Chave para espécies de Leptochloa da ESEC

1. Espiguetas 2-2,5 mm compr., antécios 2-3, lemas múticos e esverdeados .. L. panicea subsp. brachiata

1. Espiguetas 3-3,5 mm compr., antécios 3-6, lemas mucronados ou aristados e purpúreos na maturação L. scabra

Leptochloa panicea subsp. brachiata (Steud.) N.W. Snow, Novon 8(1): 79. 1998.

Figura $2 \mathrm{e}$

Planta anual. Lâmina foliar 6-24 × (0,2-)0,6-1,0 $\mathrm{cm}$. Espiguetas 2-2,5 mm compr., 2-3 antécios, lemas múticos e esverdeados.

Material selecionado: BRASIL. RIo GRANDE DO NORTE: Serra Negra do Norte, Estação Ecológica do Seridó, Estrada para Lagoa do Junco, local de vertissolo, 20IV-2007, R.C. Oliveira et al. 1887 (MOSS); ao lado do alojamento, 24-VI-2006, C.G.T. Ferreira \& G.S. Araújo 251 (MOSS).

Coletada com flores e frutos de abril a junho. Encontrada em locais úmidos de vertissolos e solos arenosos.

Renvoize (1986), sob L. filiformis (Lam.) P. Beauv. (sinônimo de Leptochloa panicea subsp. brachiata), encontrou espiguetas 1,3-2(-2,5) $\mathrm{mm}$ compr.; o material da ESEC possui espiguetas no extremo de variação, de 2-2,5 mm compr.

Leptochloa scabra Nees, Agrostogr. Bras. 2: 435. 1829.

Figura $2 \mathrm{f}$

Planta anual. Lâmina foliar 20-48 × 0,3-0,7 cm. Espiguetas 3-3,5 mm compr., 3-6 antécios; lemas mucronados ou aristados e purpúreos na maturação.

Material selecionado: BRASIL. Rio GRAnde Do Norte: Serra Negra do Norte, Estação Ecológica do Seridó, Margem do açude, 15-I-2007, C.G.T. Ferreira 305 (MOSS); estrada principal, 24-VI-2006, C.G.T. Ferreira \& G.S. Araújo 264 (MOSS).

Coletada com flores e frutos de janeiro a julho. Encontrada em solos arenosos antropizados, vertissolos e locais úmidos.

\section{Neesiochloa Pilg.}

Plantas cespitosas. Panícula laxa, com um ramo com espiguetas de primeira ordem, sem extensão apical estéril e desprovido de espiguetas. Pedicelos duas vezes mais longos que as espiguetas. 
Espiguetas solitárias, basítonas; antécios inferiores com flores bissexuadas com antécios apicais neutros ou reduzidos sem calo; articulação acima das glumas, que permanecem na inflorescência após a queda dos antécios maduros; glumas atenuadas, múticas, sem cerdas espinescentes sobre as nervuras; antécios pigmentados; lema com compressão lateral, aristas 1-7 mm compr. Estames 3.

Gênero monotípico endêmico do Nordeste do Brasil (Renvoize 1986).

Neesiochloa barbata (Nees) Pilg., Repert. Spec. Nov. Regni Veg. 48: 119. 1940.

Figura 2 m

Plantas anuais de 25-40 cm alt. Espiguetas de 5-8 mm compr., largamente oblongas, antécios progressivamente menores, lema mais largo que longo, ápice truncado, margens aladas, com tricomas longos e sedosos no $1 / 3$ proximal das nervuras.

Material selecionado: BRASIL. Rio Grande Do Norte: Serra Negra do Norte, Estação Ecológica do Seridó, Estrada do extremo sul, 14-V-2005, R.T. Queiroz 337 (MOSS, UFRN); Estrada para Lagoa do Junco, 02-VIII-2006, C.G.T. Ferreira \& M.L. Silva 274 (MOSS).

Coletada com flores e frutos de abril a agosto. Encontrada em solos arenosos e úmidos.

\section{Tragus Haller}

Plantas cespitosas. Panícula com um ramo espiciforme, sem extensão apical estéril e desprovida de espiguetas. Espiguetas sésseis reunidas em fascículos, basítonas, com um antécio com flores bissexuadas, articulação na base dos fascículos de espiguetas, a primeira gluma rudimentar, a segunda aguda ou acuminada, com cerdas espinescentes sobre as nervuras; antécios pigmentados; lemas com compressão dorsal, múticos. Estames 3. Cariopse típica.

Gênero paleotropical com oito espécies (Sulekic \& Zapater 2001), uma das quais introduzida na América (Anton 1980).

Tragus berteronianus Schult., Mant. 2: 205. 1824.

Figura $n$

Planta anual. Fascículos com 2 espiguetas; pedúnculo do fascículo ca. $0,3 \mathrm{~mm}$ compr., mais curto ou do mesmo comprimento do entrenó que separa as espiguetas. Espiguetas do fascículo de tamanhos diferentes ou subiguais; gluma superior 5-nervada.
Material selecionado: BRASIL. Rio GRANDE Do Norte: Serra Negra do Norte, Estação Ecológica do Seridó, ca. $1 \mathrm{~m}$ após vertissolo, 12-IV-2006, C.G.T. Ferreira 83 (MOSS); em frente ao alojamento, 24-VI2006, C.G.T. Ferreira \& G.S. Araújo 248 (MOSS).

Coletada com flores e frutos de abril a junho. Encontrada em solos arenosos antropizados, vertissolo, locais pedregosos e campos abertos entre populações de outras espécies.

Tripogon Roem. \& Schult.

Plantas cespitosas. Panícula com um ramo unilateral espiciforme, sem extensão apical estéril e desprovida de espiguetas. Espiguetas subsésseis, solitárias, basítonas, flores bissexuadas, plurifloras, com antécios apicais rudimentares; articulação entre os antécios e acima das glumas, que permanecem no colmo florífero após a queda dos antécios maduros; glumas agudas ou acuminadas, múticas, sem cerdas espinescentes sobre as nervuras; antécios pigmentados; lema com compressão lateral, arístulas 0,5-0,9 mm compr. Estames 3. Cariopse típica.

Clayton \& Renvoize (1989) referem-se cerca de 30 espécies para o gênero, distribuídas nos trópicos do Velho Mundo, com apenas uma espécie na América tropical.

Tripogon spicatus (Nees) Ekman, Ark. Bot. 11(4): 36. 1912.

Figura 3 o

Plantas anuais, ca. $15 \mathrm{~cm}$ alt. Lâminas foliares filiformes, concentradas na base do colmo. Lemas com ápice 2-dentado, com tricomas longos na base.

Material examinado: BRASIL. Rio GRANDE do NoRTE: Serra Negra do Norte, Estação Ecológica do Seridó, Sem local, 19-V-2005, R.T. Queiroz 350 (MOSS, UFRN); estrada para o Mirante, 21-IV-2007, R.C. Oliveira et al. 1898 (MOSS).

Coletada com flores e frutos de abril a maio. Encontrada em locais areno-pedregosos e entre formações rochosas.

VII. Paniceae

Representada, na ESEC, por 16 gêneros e 32 espécies, das quais Megathyrsus maximus (Jacq.) B.K. Simon \& W.L. Jacobs (capim-colonião, figura 2 i) e Pennisetum purpureum Schumach. (capim-elefante, figura $3 \mathrm{~g}$ ) são encontrados, apenas em locais onde há resquícios de cultivo, por isso não foram descritas. 
Chave para os gêneros de Paniceae da ESEC

1. Espiguetas em fascículos que se desprendem por completo da ráquis Anthephora

1. Espiguetas solitárias ou pareadas, caducas ou persistentes

2. Espiguetas rodeadas na base por um invólucro de cerdas livres ou concrescidas

3. Cerdas persistentes na ráquis após a queda das espiguetas maduras Setaria

3. Cerdas caducas com as espiguetas maduras

4. Cerdas plumosas e livres entre si; panícula espiciforme de 10-30 cm compr.

Pennisetum

4. Cerdas rígidas, concrescidas na base ou, no máximo, até a metade de seu comprimento; panícula espiciforme de 5-11 cm compr.

Cenchrus

2. Espiguetas sem invólucro de cerdas na base

5. Gluma inferior reduzida a uma dilatação em forma de anel na base da espigueta

Eriochloa

5. Gluma inferior presente, reduzida ou ausente, mas sem formar dilatação em forma de anel na base da espigueta

6. Panícula cilíndrica, espiciforme; lâminas foliares amplexicaules Hymenachne

6. Panícula típica ou em ramos unilaterais espiciformes; lâminas foliares não amplexicaules

7. Gluma superior ausente Reimarochloa

7. Gluma superior presente

8. Gluma inferior ausente ou reduzida

9. Espiguetas pareadas, uma subséssil e a outra pedicelada em cada par; lema superior coriáceo, com margens hialinas e bem desenvolvidas, recobrindo totalmente a pálea

Digitaria

9. Espiguetas pareadas ou solitárias, pediceladas; lema superior com margens coriáceas em toda a extensão, margens enroladas, não desenvolvidas, envolvendo brevemente a pálea que fica aparente

Paspalum

8. Gluma inferior presente

10. Gluma superior e lema inferior aristados, subcoriáceos ou cartáceos, mais consistentes que o antécio superior membranoso ou cartilaginoso Melinis

10. Gluma superior e lema inferior múticos, membranosos, menos consistentes que o antécio superior coriáceo

11. Antécio superior transversalmente rugoso

12. Inflorescência em ramos unilaterais espiciformes

13. Ráquis com uma extensão aguda e estéril; antécio superior aristulado Paspalidium

13. Ráquis com uma espigueta terminal, sem uma extensão aguda e estéril; antécio superior não aristulado Urochloa

12. Inflorescência em panícula

11. Antécio superior liso ou papiloso

14. Panículas em ramos unilaterais espiciformes

15. Panículas com 1 ramo unilateral espiciforme Mesosetum

15. Panículas com 3 ou mais ramos unilaterais espiciformes

Echinochloa

14. Panículas típicas Panicum

\section{Anthephora Schreb.}

Lâminas foliares não amplexicaules. Panícula com 1 ramo espiciforme, 6-9,5 cm compr., ráquis sem uma extensão aguda e estéril. Espiguetas sésseis, em fascículos que se desprendem por completo da ráquis, acrótonas, 2-floras, flor distal bissexuada, sem um invólucro de cerdas, caducas; gluma inferior ausente; gluma superior desenvolvida, mútica, coriácea, tão consistentes quanto o antécio superior; lema inferior glabro, mútico; antécio superior liso; lema superior, mútico, de igual consistência em toda a extensão, margens envolvendo brevemente a pálea. Estames 3. Cariopse típica. 
Clayton \& Renvoize (1989) relacionam 11 espécies na África e Ásia e uma para a América tropical.

Anthephora apresenta um invólucro endurecido, cuja origem ainda não é compreendida. Para Renvoize (1986) é constituído pelas glumas das espiguetas do fascículo.

Anthephora hermaphrodita (L.) Kuntze, Revis. Gen. Pl. 2: 759. 1891.

Figura $1 \mathrm{~b}$

Plantas anuais, cespitosas, 20-50 $\mathrm{cm}$ alt. Espiguetas em fascículos de 4 espiguetas, mas somente 2 desenvolvidas. Cariopse 1,5 × 1,2 mm, com hilo circular atro-purpúreo.

Material selecionado: BRASIL. Rio GRANDE Do Norte: Serra Negra do Norte, Estação Ecológica do Seridó, Lagoa do Junco, 2-VIII-2006. C.G.T.Ferreira \& M.L. Silva 278 (MOSS); caminho para o Mirante, 21-IV-2007, R.C. Oliveira et al. 1916 (MOSS).

Coletada com flores e frutos de abril a agosto. Encontrada em margem de estrada, local arenopedregoso, em formação rochosa, solos arenosos e úmidos e vertissolos.

\section{Cenchrus L.}

Lâminas foliares não amplexicaules. Panícula com 1 ramo espiciforme, $5-11 \mathrm{~cm}$ compr., ráquis sem uma extensão aguda e estéril. Espiguetas subsésseis, agrupadas, acrótonas, 2-floras, flor distal bissexual, incluídas num invólucro de cerdas caducas com as espiguetas maduras, concrescidas só na base ou, no máximo, até a metade de seu comprimento, cerdas e espiguetas caducas; gluma inferior presente; gluma superior e lema inferior aristulados, membranosos, menos consistentes que o antécio superior liso; lema superior mútico, de igual consistência em toda a extensão, margens envolvendo brevemente a pálea.

Gênero tropical com 22 espécies (Clayton \& Renvoize 1989). Está representado na ESEC por uma espécie.

Cenchrus ciliaris L., Mant. P1.: 302. 1771.

Figura $1 \mathrm{~g}$

Plantas perenes, com ramificações nos nós superiores. Invólucro com cerdas não espinescentes unidas só na base, cerdas atingindo mais que o dobro do comprimento da espigueta com uma cerda mais longa e larga que as demais, arroxeadas quando jovens, palhetes na maturidade.
Material selecionado: BRASIL. Rio GRANDE DO NorTE: Serra Negra do Norte, Estação Ecológica do Seridó, Estrada, 11-III-2006, C.G.T. Ferreira \& R.C. Oliveira 3 (MOSS); margem do açude, 20-V-2006, R.C. Oliveira \& C.G.T. Ferreira 1663(MOSS).

Encontrada com flores e frutos o ano todo. Coletada em margem de estrada, locais arenopedregoso, em formação rochosa e em campos arenoargilosos abertos e em locais úmidos.

Filgueiras \& Rodrigues-da-Silva (2001) ressaltaram que a espécie foi introduzida no Brasil, sendo encontrada nos Estados do Piauí, Bahia, Distrito Federal, Mato Grosso do Sul, São Paulo e Rio Grande do Sul. Portanto, relata-se pela primeira vez sua ocorrência no Rio Grande do Norte.

Na ESEC e em outras áreas do Sertão do Rio Grande do Norte, $C$. ciliaris é ruderal e muito freqüente em locais antropizados.

\section{Digitaria Heister ex Haller}

Lâminas foliares não amplexicaules. Panícula com 2-8 ramos unilaterais espiciformes, $5-15,5 \mathrm{~cm}$ compr., ráquis sem uma extensão aguda e estéril. Espiguetas pareadas, uma subséssil e outra pedicelada em cada par, 2-floras, acrótonas, flor distal bissexual, sem um invólucro de cerdas, caducas; gluma inferior ausente ou reduzida; gluma superior e lema inferior múticos, membranosos; menos consistente que o antécio superior liso; lema superior mútico, com margens hialinas recobrindo totalmente a pálea. Estames 3. Cariopse típica.

Gênero com cerca de 300 espécies de regiões tropicais e subtropicais (Canto-Dorow 2001). Está representado na ESEC por uma espécie.

Digitaria bicornis (Lam.) Roem \& Schult., Syst. Veg. 2: 470.1817.

Figura $1 \mathrm{k}$

Plantas anuais, decumbentes, enraizando nos nós inferiores. Panícula com ramos subverticilados a verticilados. Espiguetas heteromorfas, a pedicelada pilosa nas margens e alternadamente pilosa a glabra entre as nervuras laterais, a subséssil glabra ou esparsamente pilosa.

Material selecionado: BRASIL. Rio GRANDE DO NoRTE: Serra Negra do Norte, Estação Ecológica do Seridó, Estrada principal, antes do alojamento, 20-V2006, R.C. Oliveira \& C.G.T.Ferreira 1631 (MOSS); sem local, 2-VIII-2006, C.G.T. Ferreira \& M.L. Silva 271 (MOSS). 
Encontrada com flores e frutos de abril a agosto. Coletada em margem de estrada, locais arenopedregosos e em vertissolos.

Echinochloa P. Beauv.

Lâminas foliares não amplexicaules. Panícula com 3-17 ramos unilaterais espiciformes, 1,5-19 cm compr.; ráquis sem extensão aguda e estéril. Espiguetas pediceladas, solitárias, acrótonas, 2-floras, flor distal bissexual, sem um invólucro de cerdas, caducas; gluma inferior presente; gluma superior e lema inferior múticos, mucronados ou aristados, membranosos; menos consistentes que o antécio superior liso; lema superior mútico, de igual consistência em toda a extensão, margens envolvendo brevemente a pálea. Estames 3. Cariopse típica.

$\mathrm{O}$ ápice do antécio superior possui um múcron levemente reflexo, como destacado por Clayton \& Renvoize (1989).

Gênero com 30 a 40 espécies das regiões tropicais e temperadas do mundo (Clayton \& Renvoize 1989). Está representado na ESEC por duas espécies.

\section{Chave para as espécies de Echinochloa da ESEC}

1. Plantas perenes, 1-2 m alt.; lígula ciliada; antécio superior 4-5 $\mathrm{mm}$ de compr. ....................................... E. polystachya

1. Plantas anuais, $0,30-0,50 \mathrm{~m}$ alt.; lígula ausente; antécio superior 2-3 mm compr. E. colona

Echinochloa colona (L.) Link, Hort. Berol. 2: 209. 1833.

Figura 11

Plantas anuais, 0,30-0,50 m alt. Lígula ausente. Espiguetas em séries de 2. Antécio inferior neutro, lema mucronado; antécio superior 2-3 mm compr.

Material selecionado: BRASIL. Rio GRANDE DO NoRTE: Serra Negra do Norte, Estação Ecológica do Seridó, Em vertissolo, $1^{\circ}$ riacho anual seco, 23-VI2006, C.G.T. Ferreira \& G.S. Araújo 222 (MOSS); Vertissolo,23-VI-2006, C.G.T.Ferreira \& G.S.Araújo 214 (MOSS).

Coletada com flores e frutos de abril a junho. Encontrada em locais úmidos no vertissolo.

Echinochloa polystachya (Kunth) Hitchc., Contr. U.S. Natl. Herb. 22(3): 135. 1920.

Figura $1 \mathrm{~m}$
Plantas perenes, ca. 1-2 m alt., enraizando na base. Lígula ciliada. Espiguetas em série de 2 ou 4 . Antécio inferior masculino ou neutro, lema mucronado, aristulado ou longo aristado, aristas atingindo $18 \mathrm{~mm}$ compr.; antécio superior 4-5 mm compr.

Material examinado: BRASIL. Rio GRANDE do NorTE: Serra Negra do Norte, Estação Ecológica do Seridó, Margem do açude, próximo ao alojamento, 15-I2007, C.G.T. Ferreira 306 (MOSS); 19-VI-1988, A. Fernandes et al. 108 (MOSS).

Coletada com flores e frutos de janeiro a agosto. Encontrada em margem de açude.

Os espécimens da ESEC identificados como Echinochloa polystachya (figura $1 \mathrm{~m}, \mathrm{n}$ ) apresentam caracteres intermediários com E. colona (figura 1 1), destacados na tabela 1. Não há uma revisão global do gênero, o que dificulta a interpretação da variação dessa população.

Exemplares característicos de E. polystachya coletados no Rio Grande do Norte, segundo análises do material do herbário MOSS, apresentam espiguetas castanho-avermelhadas, antécio superior alvo, espigueta com aristas maiores que $4 \mathrm{~mm}$ compr., lema inferior com 7 ou mais nervuras, algumas das quais interrompidas antes de atravessarem totalmente a estrutura e indumento da espigueta conspícuo e constituído por cerdas. Os espécimens da ESEC apresentam espiguetas esverdeadas, antécio superior esverdeado, aristas muito curtas ou ausentes, indumento menos conspícuo e sete nervuras no lema inferior, sendo que duas delas não atingem a porção proximal da estrutura, como as de E. colona.

\section{Eriochloa Kunth}

Lâminas foliares não amplexicaules. Panícula com 7-9 ramos unilaterais espiciformes, 1-4,5 cm compr., ráquis sem uma extensão aguda e estéril. Espiguetas pediceladas, solitárias, acrótonas, 2-floras, flor distal bissexual, sem um invólucro de cerdas; gluma inferior reduzida a um anel geralmente vináceo na base da espigueta, caducas; gluma superior desenvolvida, mútica, membranosa; lema inferior membranoso, menos consistente que o antécio superior papiloso; lema superior aristado, de igual consistência em toda a extensão, margens envolvendo brevemente a pálea. Estames 3. Cariopse típica.

Gênero com 25 a 30 espécies de regiões tropicais e subtropicais (Longhi-Wagner 2001b), está representado na ESEC por uma espécie. 
Tabela 1. Comparação entre caracteres diagnósticos de Echinochloa polystachya e E. colona, segundo dados compilados da literatura (Hitchcock 1936, Pohl 1978, Renvoize 1984 e Boldrini 2001) e da população de E. polystachya da ESEC.

\begin{tabular}{|c|c|c|c|}
\hline Caráter & Echinochloa polystachya & E. polystachya da ESEC & E. colona \\
\hline Hábito & Perene & Perene & Anual \\
\hline Lígula & Linha de tricomas amarelados & Linha de tricomas amarelados & Ausente \\
\hline $\begin{array}{l}\text { Séries de espiguetas no ramo da } \\
\text { inflorescência }\end{array}$ & Duas & Duas ou quatro, geralmente quatro & Quatro \\
\hline Comprimento do antécio superior & $4,8-5 \mathrm{~mm}$ compr. & $4-5 \mathrm{~mm}$ compr. & $2-3 \mathrm{~mm}$ compr. \\
\hline Sexualidade do antécio inferior & Masculino & Masculino ou neutro & Neutro \\
\hline $\begin{array}{l}\text { Comprimento da arista do lema } \\
\text { inferior }\end{array}$ & 3 - $18 \mathrm{~mm}$ compr. & Ausente ou menor que $1 \mathrm{~mm}$ compr. & Ausente \\
\hline
\end{tabular}

Eriochloa punctata (L.) Desv. ex Ham., Prodr. Pl. Ind. Occid.: 5.1825

Figura 2 a

Plantas perenes, eretas ou decumbentes. Espiguetas pilosas; antécio inferior neutro, sem pálea, lema inferior com tricomas longos e esparsos, lema superior com arista de 0,8-1 mm compr., com escabrosidade retrorsa.

Material examinado: BRASIL. Rio GRANDE Do Norte: Serra Negra do Norte, Estação Ecológica do Seridó, Vertissolo, 20-V-2006, R.C. Oliveira \& C.G.T. Ferreira 1660 (MOSS); idem, 23-VI-2006, C.G.T. Ferreira \& G.S. Araújo 215 (MOSS); Trilha para a Lagoa do Junco, 23-V-2006, R.T. Queiroz 912 (MOSS, UFRN).

Coletada com flores e frutos de maio a junho. Encontrada em locais arenosos e vertissolo.

\section{Hymenachne P. Beauv.}

Lâminas foliares amplexicaules. Panícula cilíndrica, espiciforme, $27-30 \mathrm{~cm}$ compr., ráquis sem extensão aguda e estéril. Espiguetas pediceladas, solitárias, acrótonas, 2-floras, flor distal bissexual, sem um invólucro de cerdas, caducas; gluma inferior presente; gluma superior e lema inferior membranosos, múticos, com a mesma consistência do antécio superior liso; lema superior mútico, de igual consistência em toda a extensão, margens envolvendo brevemente a pálea. Estames 3. Cariopse típica.

Gênero com cinco espécies (Clayton \& Renvoize 1989) que se distribuem do México e Antilhas até o Paraguai, norte da Argentina e Brasil (Parodi 1969). Está representado na ESEC por uma espécie.

Hymenachne amplexicaulis (Rudge) Nees, Fl. Bras . Enum. Pl. 2(1): 276. 1829.

Figura $2 \mathrm{c}$
Plantas de (1,0-)1,15-1,20 m alt., decumbentes. Folhas glabras. Colo glabro. Espiguetas $(3,5)$ 3,8-4 mm compr., lanceoladas, antécio inferior neutro, pálea desenvolvida.

Material examinado: BRASIL. Rio GRANDE DO NoRTE: Serra Negra do Norte, Estação Ecológica do Seridó, Margem do açude, 19-V-2005, R.T. Queiroz 364 (MOSS, UFRN); idem, 24-X-2006, C.G.T. Ferreira 299 (MOSS).

Coletada com flores e frutos de maio a dezembro. Encontrada em locais úmidos.

Melinis P. Beauv.

Lâminas foliares não amplexicaules. Panícula típica, ráquis sem extensão aguda e estéril. Espiguetas pediceladas, solitárias, acrótonas, 2-floras, flor distal bissexuada, sem um invólucro de cerdas, caducas; gluma inferior presente; gluma superior desenvolvida, aristada, cartácea; lema inferior cartáceo, aristado, mais consistente que o antécio superior liso; lema superior mútico, de igual consistência em toda a extensão, margens envolvendo brevemente a pálea. Estames 3. Cariopse típica.

Gênero com 26 espécies paleotropicais, duas das quais amplamente difundidas na América do Sul. Melinis minutiflora P. Beauv. naturalizou-se nos trópicos úmidos. O gênero está representado na ESEC por outra espécie de grande dispersão no Brasil.

Melinis repens (Willd.) Zizka, Biblioth. Bot. 138: 55. 1988.

Figura $2 \mathrm{j}$

Plantas 30-60 cm alt. Espiguetas com gluma inferior levemente separada da gluma superior e do lema inferior pelo entrenó da ráquila. Gluma superior e 
lema inferior densamente pilosos, os tricomas rosados tornam-se esbranquiçados na maturação.

Material selecionado: BRASIL. Rio Grande Do Norte: Serra Negra do Norte, Estação Ecológica do Seridó, Estrada para o alojamento, 3-VIII-2006, C.G.T. Ferreira et al. 288 (MOSS); Lajedo dos Tanques, 21IV-2007, R.C. Oliveira et al. 1903 (MOSS).

Coletada com flores e frutos de março a agosto. Encontrada em locais antropizados areno-pedregosos, em formações rochosas e em campo formando população entre espécies nativas.

Muito citada na literatura pelo nome Rhynchelytrum repens (Willd.) C.E. Hubb, atualmente aceito como sinônimo de Melinis por vários autores (e.g. Zizca 1988, Zuloaga \& Morrone 2003).

\section{Mesosetum Steud.}

Lâminas foliares não amplexicaules. Panícula com um ramo unilateral espiciforme, 2,3-12 cm compr.; ráquis sem extensão aguda e estéril. Espiguetas pediceladas, solitárias, acrótonas, 2-floras, flor distal bissexual, sem um invólucro de cerdas, caducas; glumas desenvolvidas, múticas, membranosas; lema inferior membranoso, menos consistente que o antécio superior papiloso; lema superior mútico, de igual consistência em toda a extensão, margens envolvendo brevemente a pálea. Estames 3. Cariopse típica.

Gênero com 25 espécies do México até o nordeste da Argentina (Filgueiras 1989). Está representado por duas espécies na ESEC.

Chave para as espécies de Mesosetum da ESEC

1. Panícula com ramo espiciforme de 2,5-12 cm compr.; espiguetas 3,5-4 $\mathrm{mm}$ compr.; antécio inferior sem pálea M. annuum

1. Panícula com ramo espiciforme de 2,3-5 cm compr.; espiguetas $2,8-3,5$ $\mathrm{mm}$ compr.; antécio inferior com pálea bem desenvolvida ......... M. pappophorum

Mesosetum annuum Swallen, Brittonia 2(4): 377. 1937.

Figura $2 \mathrm{k}$

Plantas anuais, cespitosas. Panícula com ramo espiciforme de 2,5-12 cm compr. Espiguetas 3,5-4 mm compr.; gluma inferior assimétrica, truncada, com tricomas longos no $1 / 3$ inicial da nervura central, os tricomas distais mais longos que os proximais; antécio inferior sem pálea.

Material examinado: BRASIL. Rio GrandE do NoRTE: Serra Negra do Norte, Estação Ecológica do Seridó, Caminho para Lajedo dos Tanques, 21-IV-2007, R.C. Oliveira et al. 1911 (MOSS).

Coletada com flores e frutos em abril. Encontrada em campos arenosos e úmidos, formando grandes populações.

Mesosetum annuum foi citada anteriormente apenas para Goiás, Maranhão e Piauí (Filgueiras 1989), tratando-se de uma nova ocorrência para o Estado do Rio Grande do Norte.

É relacionada a M. loliiforme (Hochst. ex Steud.) Chase e M. chlorostachyum (Döll) Chase. Distinguese de $M$. loliiforme pelo hábito, perene nesta e anual em M. annuum. Mesosetum chlorostachyum tem distribuição restrita ao norte do Brasil e Venezuela, possui a gluma inferior subulada, com superfície geralmente glabra, enquanto, nas outras duas espécies, a gluma inferior é assimétrica, provida de tricomas proximais (Filgueiras 1989).

Mesosetum pappophorum (Nees) Kuhlm., Comm.

Lin. Telegr., Bot. 67(11): 90. 1922.

Figura 21

Plantas anuais. Panícula com ramo espiciforme de 2,3-5 cm compr. Espiguetas 2,8-3,5 mm compr., gluma inferior assimétrica, aguda, com tricomas proximais e ao longo de quase toda a nervura central, os tricomas distais da nervura mais longos que os proximais; antécio inferior com pálea bem desenvolvida.

Material selecionado: BRASIL. Rio GRAnde Do NoRTE: Serra Negra do Norte, Estação Ecológica do Seridó, $100 \mathrm{~m}$ após a entrada na margem da estrada, 20-V-2006, R.C. Oliveira \& C.G.T. Ferreira 1642 (MOSS); sem local, 24-VI-2006, C.G.T. Ferreira \& G.S. Araújo 254 (MOSS).

Coletada com flores e frutos de maio a julho. Encontrada em campos abertos e úmidos, formando grandes populações, algumas vezes associadas a $M$. annuum.

Espécie característica da Caatinga e pouco freqüente, provavelmente, pela preferência por parte dos animais pastadores. 


\section{Panicum L.}

Lâminas foliares não amplexicaules. Panícula típica, laxa, 6-21 cm compr., ráquis sem uma extensão aguda e estéril. Espiguetas pediceladas, solitárias, acrótonas, 2-floras, flor distal bissexual, caducas, sem um invólucro de cerdas; gluma inferior presente; gluma superior e lema inferior desenvolvidos, múticos, membranosos, menos consistentes que o antécio superior liso ou papiloso; lema superior mútico, de igual consistência em toda a extensão, margens envolvendo brevemente a pálea. Estames 3 . Cariopse típica.

Adotando a circunscrição de Panicum proposta por Aliscione et al. (2003), Guglieri et al. (2007) relacionaram ao gênero 400 espécies pantropicais, algumas das quais estendendo-se até as regiões subtropicais e temperadas. Está representado na ESEC por quatro espécies.

\section{Chave para as espécies de Panicum da ESEC}

1. Lâminas foliares cordadas; espiguetas 1-1,4 mm compr. P. trichoides

1. Lâminas foliares linear-lanceoladas; espiguetas $1,6 \mathrm{~mm}$ ou mais de comprimento

2. Gluma superior caduca; antécio superior atro-purpúreo na maturação P. exiguum

2. Gluma superior persistente; antécio superior esverdeado ou castanho na maturação

3. Plantas decumbentes; bainhas e lâminas foliares hirsutas, com pilosidade evidente a olho $\mathrm{nu}$; antécio superior coriáceo P. stramineum

3. Plantas eretas; bainhas e lâminas foliares glabras; antécio superior subcoriáceo P. dichotomiflorum

Panicum dichotomiflorum Michx., Fl. Bor.-Amer. 1: 48.1803.

Figura $2 n$

Plantas eretas, anuais. Bainhas foliares glabras; lâminas linear-lanceoladas, glabras. Panícula 12-18 $\mathrm{cm}$ compr. Espiguetas 2,6 × 1,0 mm; gluma superior persistente; antécio superior subcoriáceo, esverdeado ou palhete na maturação.

Material examinado: BRASIL. RIo GRANDE DO NORTE: Serra Negra do Norte, Estação Ecológica do Seridó, Estrada para Lagoa do Junco, 20-IV-2007, R.C. Oliveira et al. 1881 (MOSS).

Coletada com flores e frutos em abril. Encontrada em solos arenosos e úmidos.

Panicum exiguum Mez, Bot. Jahrb. Syst. 56(Beibl. 125): 3. 1921.

Figura 2 o

Plantas eretas, anuais. Bainhas foliares tuberculado-hirsutas, pilosidade evidente a olho nu; lâminas linear-lanceoladas, tuberculado-pilosas a hirsutas, pilosidade evidente a olho nu. Panícula 8-18 cm compr. Espiguetas 3,5-3,7 × 1,6-1,9 mm; gluma superior caduca; antécio superior coriáceo, atropurpúreo na maturação.
Material selecionado: BRASIL. Rio GRAnde do Norte: Serra Negra do Norte, Estação Ecológica do Seridó, Estrada principal de acesso, 20-V-2006, R.C. Oliveira \& C.G.T. Ferreira 1634 (MOSS); 50 $\mathrm{m}$ antes do Mirante, 23-VI-2006, C.G.T. Ferreira \& G.S. Araújo 182 (MOSS).

Coletada com flores e frutos de maio a julho. Encontrada em locais arenosos, úmidos e sombreados, menos freqüentemente em campos abertos e locais antropizados.

Panicum stramineum Hitchc. \& Chase, Contr. U.S. Natl. Herb. 15: 67, fig. 50. 1910.

Figura $2 \mathrm{p}$

Plantas decumbentes. Bainhas foliares estrigosas, pilosidade evidente a olho nu; lâminas linearlanceoladas, estrigosas, pilosidade evidente a olho nu. Panícula 18-21 cm compr. Espiguetas ca. 3,1 $\times$ 1,2 mm; gluma superior persistente; antécio superior coriáceo, esverdeado a palhete na maturação.

Material examinado: BRASIL. Rio GRANDE do NoRTE: Serra Negra do Norte, Estação Ecológica do Seridó, Estrada para Lagoa do Junco, 20-IV-2007, R.C. Oliveira et al. 1886 (MOSS).

Coletada com flores e frutos em abril. Encontrada em solos arenosos e úmidos. 
Os exemplares de Panicum stramineum coletados na ESEC apresentam extremos de variação não observados nos materiais estudados por Guglieri et al. (2006). Segundo a descrição desses autores, $P$. stramineum apresenta inflorescência de 7,5-12,5 cm compr., espiguetas de 2,2-2,8 $\mathrm{mm}$ de comprimento e gluma superior 9-11 nervada. O material proveniente da ESEC apresentou inflorescência atingindo 18 $\mathrm{cm}$ de comprimento, espiguetas de $3,1 \mathrm{~mm}$ de comprimento, gluma superior 7-nervada, lema inferior com $3 \mathrm{~mm}$ de comprimento, 7-9-nervado e pálea inferior de $0,8 \mathrm{~mm}$ de comprimento. $\mathrm{O}$ menor número de nervuras da gluma superior e do lema inferior torna o material do Seridó muito próximo de Panicum ephemeroides Zuloaga \& Morrone. Panicum ephemeroides é conhecida apenas do holótipo, proveniente de Goiás, segundo Guglieri et al. (2006). Apresenta lâminas foliares involutas, glabras, com até $0,2 \mathrm{~cm}$ de comprimento, lígula com tricomas no dorso e espiguetas de 3,5-3,6 mm de comprimento. Os materiais de $P$. stramineum da ESEC apresentam lâminas planas, hirsutas, de 0,6-1 cm de comprimento, lígula com tricomas no dorso.

Segundo Guglieri et al. (2006), Panicum stramineum é de ocorrência rara no Brasil. Conforme nossas observações de campo, a raridade de coletas deve estar associada ao efêmero período de florescimento desta espécie anual, já que é freqüente na área, mas, por um curto período de tempo.

Panicum trichoides Sw., Prodr.: 24. 1788.

Figura $2 \mathrm{q}$

Plantas decumbentes ou eretas, anuais. Bainhas foliares glabras; lâminas cordadas, glabras. Panícula 6-17 cm compr. Espiguetas 1-1,4 × 0,5-0,7 mm; gluma superior persistente; antécio superior coriáceo, esverdeado ou palhete na maturação.

Material selecionado: BRASIL. Rio GRANDE Do Norte: Serra Negra do Norte, Estação Ecológica do Seridó, Riacho das Traíras, 20-V-2005, R.T. Queiroz 378 (MOSS, UFRN); Lajedo dos Tanques, 21-IV2007, R.C. Oliveira et al. 1902 (MOSS);

Coletada com flores e frutos de abril a junho. Encontrada em locais arenosos, úmidos e sombreados.

\section{Paspalidium Stapf}

Lâminas foliares não amplexicaules. Panícula com (4-)10-19 ramos unilaterais espiciformes, 1-3,5 cm compr., a ráquis com uma extensão aguda e estéril. Espiguetas pediceladas, solitárias, acrótonas, 2-floras, flor distal bissexual, caducas, sem um invólucro de cerdas; gluma inferior presente; gluma superior desenvolvida, mútica, membranosa; lema inferior mútico, membranoso, menos consistente que o antécio superior rugoso; lema superior aristulado, de igual consistência em toda a extensão, margens envolvendo brevemente a pálea. Estames 3. Cariopse típica.

Gênero com cerca de 40 espécies dos trópicos (Clayton \& Renvoize 1989). Está representado na ESEC por uma espécie.

Paspalidium geminatum (Forssk.) Stapf, Fl. Trop. Afr. 9: 583. 1920.

Figura 3 a

Plantas anuais, decumbentes, com as lâminas foliares distribuídas ao longo do colmo; lígula ciliada. Espiguetas elíptico-ovais, 2-2,2 mm compr.; gluma inferior 1-3 nervada.

Material selecionado: BRASIL. Rio GRANDE DO NoRTE: Serra Negra do Norte, Estação Ecológica do Seridó, Margem do açude, 19-VI-1988, A. Fernandes et al. 105 (MOSS); idem, 28-XII-2006, C.G.T. Ferreira 303 (MOSS).

Coletada com flores e frutos de junho a janeiro. Encontrada em locais úmidos, formando pequenas populações isoladas.

A forma do ápice da gluma inferior varia de aguda a truncada, podendo ser levemente inflada. A maioria dos autores consultados (Hitchcock 1936, sob Panicum geminatum Forsk., Gould 1968, Burger \& Pohl 1980, Renvoize 1984), não mencionam o caráter, constante no material da ESEC, do lema superior aristulado.

\section{Paspalum L.}

Lâminas foliares não amplexicaules. Panícula com 2-7 ramos unilaterais espiciformes, 1,5-16 cm compr., ráquis sem extensão aguda e estéril. Espiguetas pediceladas, solitárias ou pareadas, acrótonas, 2-floras, flor distal bissexual, caducas, sem um invólucro de cerdas; gluma inferior ausente; gluma superior desenvolvida, mútica, membranosa; lema inferior mútico, membranoso ou cartilaginoso, menos consistente que o antécio superior liso ou papiloso; lema superior mútico, de igual consistência em toda a extensão, margens envolvendo brevemente a pálea. Estames 3. Cariopse típica.

O gênero engloba, aproximadamente, 400 espécies tropicais e subtropicais com ampla distribuição e diversidade no continente americano (Chase 1929). Está representado na ESEC por cinco espécies. 


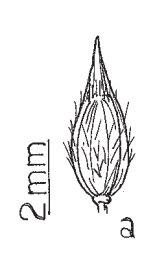

a
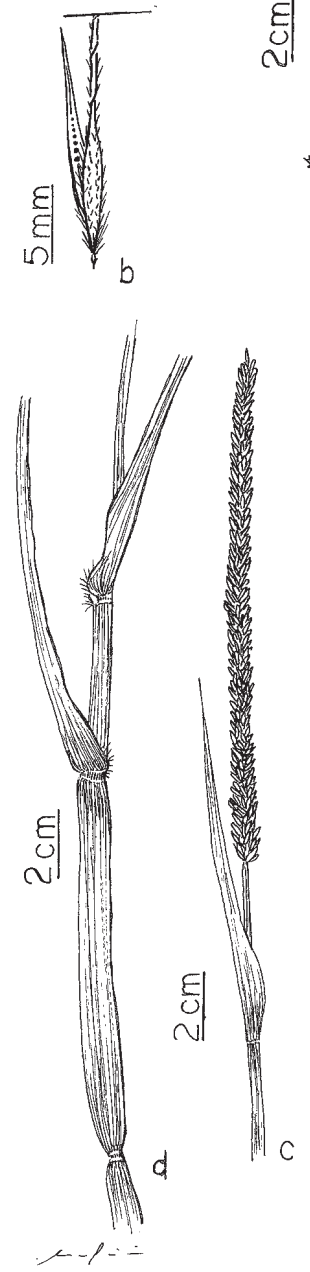

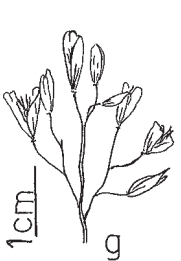

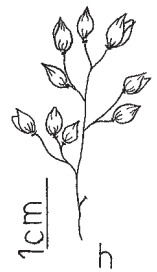

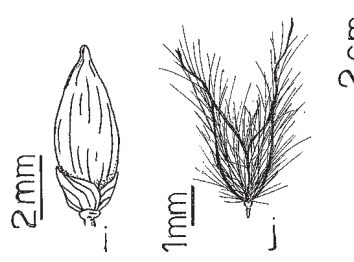

돈
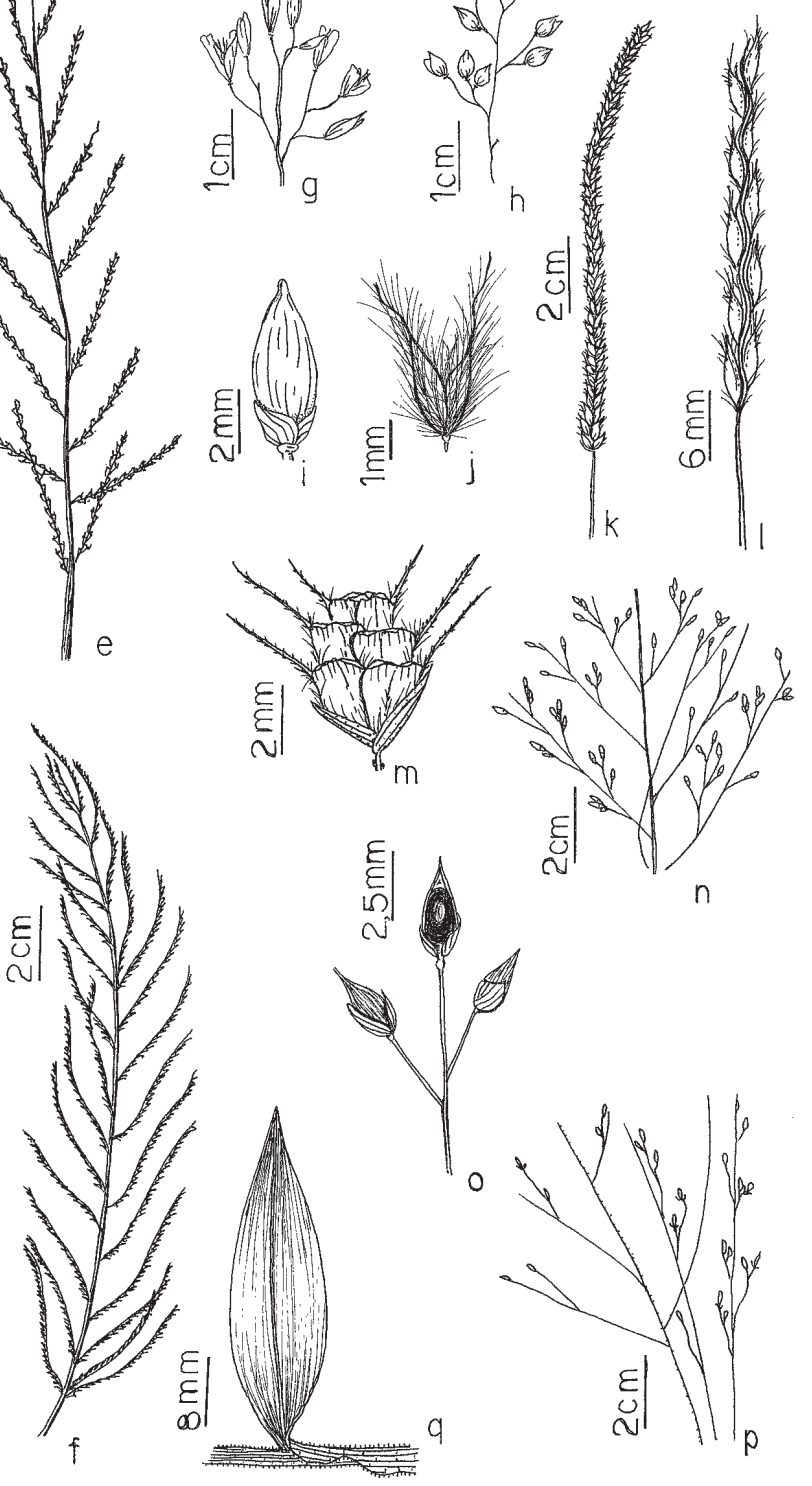

n

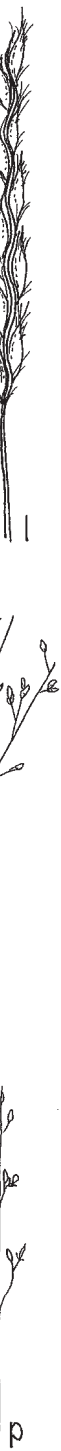

Figura 2. Espécies de Poaceae da Estação Ecológica do Seridó, RN, Brasil. a. Eriochloa punctata, espigueta. b. Heteropogon melanocarpus, par de espiguetas (arista representada parcialmente). c-d. Hymenachne amplexicaulis. c. inflorescência. d. parte do caule com folhas. e. Leptochloa panicea, inflorescência. f. Leptochloa scabra, inflorescência. g-h. Luziola brasiliensis. g. inflorescência masculina. h. inflorescência feminina. i. Megathyrsus maximus, espigueta. j. Melinis repens, espigueta. k. Mesosetum annuum, inflorescência. 1. M. pappophorum, inflorescência. m. Neesiochloa barbata, espigueta. n. Panicum dichotomiflorum, inflorescência. o.P. exiguum, espigueta.p. P. stramineum, inflorescência. q. P. trichoides, folha (a: Ferreira \& Araújo 215; b: Ferreira \& Araújo 188; c-d: Ferreira 299; e: Ferreira \& Araújo 251; f: Ferreira 305; g-h: Ferreira \& Araújo 226; i: Ferreira 300; j: Ferreira et al. 288; k: Oliveira et al. 1911 ; 1: Ferreira \& Araújo 254; m: Ferreira \& Silva 274; n: Oliveira et al. 1881; o: Ferreira \& Araújo 182; p: Oliveira et al. 1886; q: Oliveira et al. 1902).

Figure 2. Species of Poaceae from the "Seridó" Ecological Station, Rio Grande do Norte, Brazil. a. Eriochloa punctata, spikelet; b. Heteropogon melanocarpus, pair of spikelets (awn partially); c-d. Hymenachne amplexicaulis. c. inflorescence.d. part of the stem with leaves; e. Leptochloa panicea, inflorescence; f. L. scabra, inflorescence; g-h. Luziola brasiliensis. g. male inflorescence. h. female inflorescence; i. Megathyrsus maximus, spikelet; j. Melinis repens, spikelet; k. Mesosetum annuum, inflorescence; 1. M. pappophorum, inflorescence; m. Neesiochloa barbata, spikelet; n. Panicum dichotomiflorum, inflorescence; o. P. exiguum, spikelet; p. P. stramineum, inflorescence; q. P. trichoides, leaf (a: Ferreira \& Araújo 215; b: Ferreira \& Araújo 188; c-d: Ferreira 299; e: Ferreira \& Araújo 251; f: Ferreira 305; g-h: Ferreira \& Araújo 226; i: Ferreira 300; j: Ferreira et al. 288; k: Oliveira et al. 1911; 1: Ferreira \& Araújo 254; m: Ferreira \& Silva 274; n: Oliveira et al. 1881; o: Ferreira \& Araújo 182; p: Oliveira et al. 1886; q: Oliveira et al. 1902). 
Chave para as espécies de Paspalum da ESEC

1. Gluma superior alada

P. fimbriatum

1. Gluma superior áptera

2. Espigueta escudada

P. scutatum

2. Espigueta elíptica ou oboval

3. Espigueta com tricomas clavados

P. clavuliferum

3. Espigueta glabra ou com tricomas não clavados

4. Plantas perenes; antécio superior esverdeado

P. ligulare

4. Plantas anuais; antécio superior castanho-escuro

P. melanospermum

Paspalum clavuliferum C. Wright, Anales Acad. Ci. Med. Habana 8: 203. 1871.

Figura $3 \mathrm{~b}$

Plantas anuais. Espigueta elíptico-oboval, com tricomas clavados; gluma superior áptera; antécio superior esverdeado ou palhete.

Material examinado: BRASIL. Rio GRANDE do NoRTE: Serra Negra do Norte, Estação Ecológica do Seridó, Estrada para Lagoa do Junco, 20-IV-2007, R.C. Oliveira et al. 1876 (MOSS); idem, 20-IV-2007, R.C. Oliveira et al. 1880 (MOSS).

Coletada com flores e frutos em abril. Encontrada em solos arenosos e úmidos.

Paspalum fimbriatum Kunth, Nov. Gen. Sp. (quarto ed.) 1: 93, pl. 28. 1815 [1816].

Figura $3 \mathrm{c}$

Plantas anuais. Espigueta oval, glabras; gluma superior alada, as asas ciliadas e geralmente laceradas; antécio superior esverdeado.

Material selecionado: Em frente ao alojamento, 24VI-2006, C.G.T.Ferreira \& G.S.Araújo 245 (MOSS); Caminho para o Mirante, 21-IV-2007, R.C. Oliveira et al. 1912 (MOSS).

Coletada com flores e frutos de março a julho. Encontrada em locais areno-pedregosos antropizados, vertissolos e campos abertos, formando pequenas populações.

Apresenta gluma superior e lema inferior cartilaginosos, principalmente nas fímbrias.

Paspalum ligulare Nees, Fl. Bras. Enum. Pl. 2(1): 60.1829.

Figura 3 d

Plantas perenes. Espiguetas elípticas, glabras; gluma superior áptera; antécio superior esverdeado.
Material examinado: BRASIL. Rio Grande do NoRTE: Serra Negra do Norte, Estação Ecológica do Seridó, Vertissolo, 20-V-2006, R C. Oliveira \& C.G.T. Ferreira 662 (MOSS); idem, 23-VI-2006, C.G.T. Ferreira \& G.S. Araújo 218 (MOSS).

Coletada com flores e frutos de maio a junho. Encontrada em um único ambiente de vertissolo em um local de um riacho anual seco.

Paspalum melanospermum Desv. ex Poir., Encycl., Suppl. 4(1): 315. 1816.

Figura 3 e

Plantas anuais. Espigueta oboval ou amplamente oboval, glabra ou pilosa; gluma superior áptera; antécio superior castanho-escuro.

Material selecionado: BRASIL. Rio GRAnde do NorTE: Serra Negra do Norte, Estação Ecológica do Seridó, Estrada principal, próximo ao alojamento, 20-V-2006, R.C. Oliveira \& C.G.T. Ferreira 1646 (MOSS); Estrada para o Lajedo dos Tanques, 24-VI2006, C.G.T. Ferreira \& G.S. Araújo 238 (MOSS).

Coletada com flores e frutos de abril a julho. Encontrada em locais areno-pedregosos, vertissolos, locais antropizados, em campos abertos.

Paspalum scutatum Nees ex Trin., Gram. Panic.: 105. 1826

Figura $3 \mathrm{f}$

Plantas anuais. Espiguetas escudadas, glabras; gluma superior áptera; antécio superior esverdeado.

Material selecionado: BRASIL. Rio GRANDE DO NorTE: Serra Negra do Norte, Estação Ecológica do Seridó, Estrada para o Lajedo dos Tanques, 24-VI2006, C.G.T. Ferreira \& G.S. Araújo 239 (MOSS); Caminho para o Mirante, 21-IV-2007, R.C. Oliveira et al. 1914 (MOSS). 
Coletada com flores e frutos de abril a junho. Encontrada em locais areno-pedregosos antropizados, em campos abertos e em formações pedregosas de serra.

\section{Reimarochloa Hitchc.}

Lâminas foliares não amplexicaules. Panícula com até 12 ramos unilaterais espiciformes, 2-3 cm compr., ráquis sem extensão aguda e estéril. Espiguetas sésseis, solitárias, acrótonas, 2-floras, flor distal bissexuada, caducas, sem invólucro de cerdas; glumas inferior e superior ausentes; lema inferior mútico, membranoso, da mesma consistência que o antécio superior liso; lema superior mútico, de igual consistência em toda a extensão, margens envolvendo brevemente a pálea. Estames 3. Cariopse típica.

Gênero com quatro espécies, que ocorrem do sul dos Estados Unidos até a Argentina (Clayton \& Renvoize 1989). Na ESEC, está representada por uma espécie.

Reimarochloa brasiliensis (Spreng.) Hitchc., Contr. U.S. Natl. Herb. 12(6): 198. 1909.

Figura 3 h.

Plantas anuais, prostradas, radicantes, ca. 30 $\mathrm{cm}$ alt.; nós barbados. Lâminas foliares pilosas, distribuídas por todo o colmo. Espiguetas lanceoladas, ca. 1,9 $\times 0,3 \mathrm{~mm}$, com tricomas tuberculados sobre as nervuras do lema inferior e no $1 / 3$ inicial da nervura central do lema superior. Panícula com ramos unilaterais eretos ou, mais raramente, divergentes.

Material examinado: BRASIL. RIo GRANDE do NORTE: Serra Negra do Norte, Estação Ecológica do Seridó, Margem do açude, 24-I-2006, R.C. Oliveira et al. 1611(MOSS); idem, 15-I-2007, C.G.T. Ferreira 304 (MOSS).

Coletada com flores e frutos em janeiro. Encontrada na margem de açude em período de seca.

Reimarochloa brasiliensis (Spreng.) Hitchc. (figura $3 \mathrm{~h}$ ) foi sinonimizada sob R. acuta (Flüggé) Hitchc. por Zuloaga \& Morrone (2003). No entanto, a experiência de um dos presentes autores no pantanal-matogrossense, onde $R$. acuta e $R$. brasiliensis são abundantes e simpátricas, reafirma os caracteres observados e ilustrados por Döll (1877), corroborando a separação dessas espécies. Reimarochloa acuta possui colmos decumbentes até quase eretos e os ramos da inflorescência tendem a ser reflexos. Reimarochloa brasiliensis possui colmos prostrados, radicantes, mais longos, ascendentes apenas nas extremidades distais e os ramos da inflorescência, em maior número, são, em sua maioria, eretos.

Setaria P. Beauv.

Lâminas foliares não amplexicaules. Panícula espiciforme com 1 ramo de 2-8 cm compr., ráquis sem uma extensão aguda e estéril. Espiguetas sésseis, agrupadas, acrótonas, 2-floras, flor distal bissexual, caducas, com cerdas involucrais livres entre si e persistentes na ráquis após a queda das espiguetas maduras; gluma inferior presente; gluma superior desenvolvida, mútica, membranosa; lema inferior glabro, mútico, membranoso, menos consistente que o antécio superior rugoso, lema superior mútico, de igual consistência em toda a extensão, margens envolvendo brevemente a pálea. Estames 3. Cariopse típica.

Segundo Pensiero (1999), Setaria inclui ao redor de 110 espécies da regiões tropicais, subtropicais e temperadas do mundo, com centros de diversidade na África e América do Sul. Está representado na ESEC por duas espécies.

Chave para as espécies de Setaria da ESEC

1. Planta perene; espiguetas acompanhadas por 4-11 cerdas antrorso-escabras, não aderentes S. parviflora

1. Planta anual; espiguetas acompanhadas por 1-3 cerdas retrorso-escabras, aderentes S. scandens

Setaria parviflora (Poir.) Kerguélen, Lejeunia, n.s. 120: 161. 1987.

Figura 3 i

Planta perene. Espiguetas 1,6-2,8 $\mathrm{mm}$ compr., acompanhadas por 4-11 cerdas antrorso-escabras, não aderentes.

Material selecionado: BRASIL. Rio GRANDE Do Norte: Serra Negra do Norte, Estação Ecológica do Seridó, $50 \mathrm{~m}$ antes do Mirante, 23-VI-2006, C.G.T. Ferreira \& G.S. Araújo 189 (MOSS); estrada para Lagoa do Junco, 20-IV-2007, R.C. Oliveira et al. 1884 (MOSS).

Coletada com flores e frutos de maio a junho. Encontrada em solos arenosos e úmidos, sendo observada inclusive em locais antropizados. 
Setaria scandens Schrad., Mant. 2: 279. 1824.

Figura $3 \mathrm{j}$

Planta anual. Espiguetas 1,3-1,6 mm compr., acompanhadas por 1-3 cerdas retrorso-escabras, aderentes.

Material examinado: BRASIL. RIo GRANDE Do NoRTE: Serra Negra do Norte, Estação Ecológica do Seridó, Casa da entrada, 17-IV-2006, R.T. Queiroz 744 (MOSS); estrada para o Mirante, 21-IV-2007, R.C. Oliveira et al. 1894 (MOSS).

Coletada com flores e frutos de abril a maio. Encontrada em solos arenosos e úmidos, sendo observada inclusive em locais antropizados.

Urochloa P. Beauv.

Lâminas foliares não amplexicaules. Panícula típica ou com 3-20 ramos unilaterais espiciformes,
2,5-7 cm compr., ráquis sem uma extensão aguda e estéril. Espiguetas pediceladas, solitárias ou pareadas, acrótonas, 2-floras, flor distal bissexual, caducas, sem cerdas involucrais; gluma inferior presente; gluma superior desenvolvida, mútica, membranosa; lema inferior, mútico, membranoso, menos consistente que o antécio superior rugoso; lema superior mútico, de igual consistência em toda a extensão, margens envolvendo brevemente a pálea. Estames 3. Cariopse típica.

Urochloa distribui-se por ambos os hemisférios, ocorrendo 16 espécies no Brasil (Sendulsky 1978). Na ESEC, o gênero está representado por quatro espécies, duas introduzidas - Urochloa mutica (Forssk.) T.Q. Nguyen e Urochloa plantaginea (Link) R.D. Webster - e duas nativas.

\section{Chave para as espécies de Urochloa da ESEC}

1. Inflorescência em panícula típica

2. Espiguetas 2-3,2 mm compr., glabras U. fusca

2. Espiguetas 3-4 mm compr., pilosas U. mollis

1. Inflorescência em ramos unilaterais espiciformes

3. Planta perene com bainhas hirsutas; inflorescência com 5-20 ramos unilaterais espiciformes com ramificações secundárias U. mutica

3. Planta anual, com bainhas glabras; inflorescência com 2-8 ramos unilaterais espiciformes, sem ramificações secundárias U. plantaginea

Urochloa fusca (Sw.) B.F. Hansen \& Wunderlin, Novon 11(3): 368. 2001.

Figura $3 p$

Planta anual, bainhas glabras ou levemente pilosas. Inflorescência em panícula típica. Espiguetas obtusas, 2-3,2 mm compr., glabras. Espiguetas e antécio superior castanhos.

Material selecionado: BRASIL. Rio GRAnde DO NoRTE: Serra Negra do Norte, Estação Ecológica do Seridó, Trilha da Caveira, 12-IV-2006, C.G.T.Ferreira 76 (MOSS); em frente ao alojamento, 24-VI-2006, C.G.T. Ferreira \& G.S. Araújo 249 (MOSS).

Coletada com flores e frutos de março a junho. Encontrada em locais arenosos antropizados, vertissolos, beira de estradas, serra, sendo observada também em locais pedregosos e campos úmidos.
Urochloa mollis (Sw.) Morrone \& Zuloaga, Darwiniana 33(1-4): 85. 1992.

Figura $3 \mathrm{q}$

Planta anual, bainhas glabras ou levemente pilosas. Inflorescência em panícula típica. Espiguetas ovais, 3-4 mm compr., pilosas, amareladas, apenas o ápice e margens superiores escurecidos, antécio palhete.

Material selecionado: BRASIL. Rio GRAnde Do NoRTE: Serra Negra do Norte, Estação Ecológica do Seridó, Estrada para o Lajedo dos Tanques, 24-VI2006, C.G.T. Ferreira \& G.S. Araújo 234 (MOSS); em frente ao alojamento, 24-VI-2006, C.G.T.Ferreira \& G.S. Araújo 250 (MOSS).

Coletada com flores e frutos de março a junho. Encontrada em solos arenosos antropizados, serra, beira de estradas e vertissolos. 


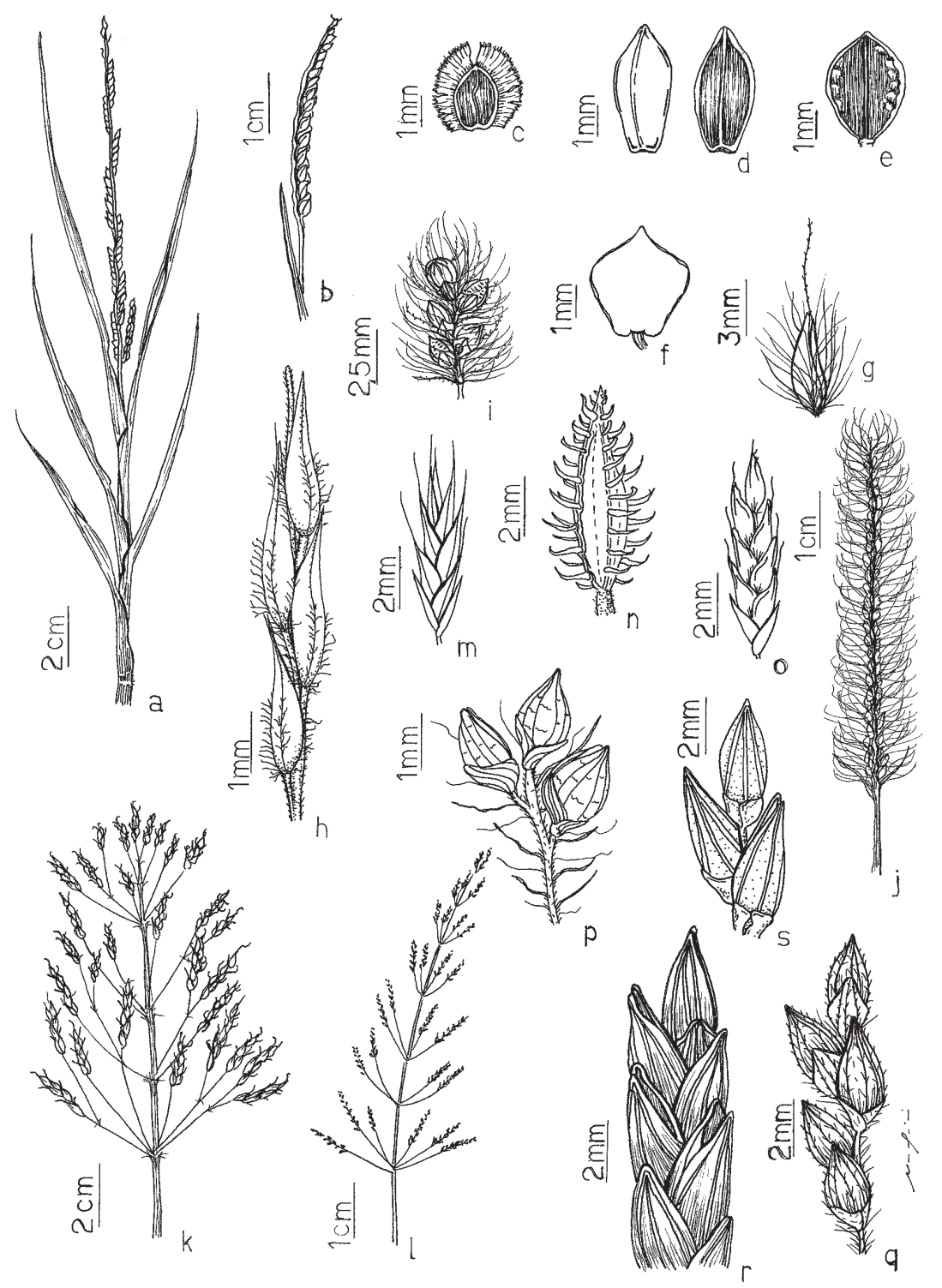

Figura 3. Espécies de Poaceae da Estação Ecológica do Seridó, RN, Brasil. a. Paspalidium geminatum, fragmento de um colmo. b. Paspalum clavuliferum, inflorescência. c. P. fimbriatum, espigueta. d. P. ligulare, espigueta vista dorsal e ventral, respectivamente. e. P. melanospermum, espigueta. f. P. scutatum, espigueta. g. Pennisetum purpureum, espigueta e invólucro de cerdas. h. Reimarochloa brasiliensis, espiguetas. i. Setaria parviflora, espiguetas. j. S. scandens, espiguetas. k. Sorghum arundinaceum, inflorescência. 1. Sporobolus pyramidatus, inflorescência. m. Steirachne diandra, espigueta. n. Tragus berteronianus, espigueta. o. Tripogon spicatus, espigueta. p. Urochloa fusca, espiguetas. q. U. mollis, espiguetas. r. U. mutica, espiguetas. s. U. plantaginea, espiguetas (a: Ferreira 303; b: Oliveira et al. 1880; c: Ferreira \& Araújo 245; d: Ferreira \& Araújo 218; e: Ferreira \& Araújo 238; f: Ferreira \& Araújo 239; g: Ferreira \& Araújo 282; h: Ferreira 304; i: Ferreira \& Araújo 189; j: Oliveira et al. 1894; k: Ferreira et al. 292; 1: Oliveira \& Ferreira 1668; m: Ferreira et al. 286; n: Ferreira \& Araújo 248; o: Oliveira et al. 1898; p: Ferreira \& Araújo 249; q: Ferreira \& Araújo 234; r: Ferreira et al. 291; s: Ferreira \& Araújo 243).

Figure 3. Species of Poaceae from the "Seridó" Ecological Station, Rio Grande do Norte, Brazil. a. Paspalidium geminatum, fragment of a stem; b. Paspalum clavuliferum, inflorescence; c. P. fimbriatum, spikelet; d. P. ligulare, spikelet, dorsal and ventral view, respectively; e. P. melanospermum, spikelet; f. P. scutatum, spikelet; g. Pennisetum purpureum, spikelet and involucre of bristles; h. Reimarochloa brasiliensis, spikelets; i. Setaria parviflora, spikelets; j. S. scandens, spikelets; k. Sorghum arundinaceum, inflorescence; 1. Sporobolus pyramidatus, inflorescence; $m$. Steirachne diandra, spikelet; $n$. Tragus berteronianus, spikelet; o. Tripogon spicatus, spikelet; $\mathrm{p}$. Urochloa fusca, spikelets; q. U. mollis, spikelets; r. U. mutica, spikelets; s. U. plantaginea, spikelets (a: Ferreira 303; b: Oliveira et al. 1880 ; c: Ferreira \& Araújo 245; d: Ferreira \& Araújo 218; e: Ferreira \& Araújo 238; f: Ferreira \& Araújo 239; g: Ferreira \& Araújo 282; h: Ferreira 304; i: Ferreira \& Araújo 189; j: Oliveira et al. 1894; k: Ferreira et al. 292; 1: Oliveira \& Ferreira 1668; m: Ferreira et al. 286; n: Ferreira \& Araújo 248; o: Oliveira et al. 1898; p: Ferreira \& Araújo 249; q: Ferreira \& Araújo 234; r: Ferreira et al. 291; s: Ferreira \& Araújo 243). 
Urochloa mutica (Forssk.) T.Q. Nguyen, Novosti Sist. Vyssh. Rast.: 13. 1966.

Figura $3 \mathrm{r}$

Plantas perenes, com bainhas hirsutas. Inflorescência com 5-20 ramos unilaterais espiciformes, ramificações secundárias presentes. Espiguetas ovais, 3-3,5 mm compr., glabras.

Material selecionado: BRASIL. Rio GRANDE Do NorTE: Serra Negra do Norte, Estação Ecológica do Seridó, Margem do açude, 24-VI-2006, C.G.T. Ferreira \& G.S. Araújo 244 (MOSS); dentro do açude, 3-VIII2006, C.G.T. Ferreira et al. 291(MOSS).

Coletada com flores e frutos de maio a agosto. Encontrada como planta aquática e na margem úmida de açude. Introduzida e subespontânea.

Urochloa plantaginea (Link) Webster, Syst. Bot. 13(4): 606. 1988.

Figura $3 \mathrm{~s}$

Plantas anuais com bainhas glabras. Inflorescência com 2-8 ramos unilaterais espiciformes, sem ramificações secundárias. Espiguetas elípticas, 4-6 mm compr., glabras.

Material selecionado: BRASIL. Rio GRAnde Do Norte: Serra Negra do Norte, Estação Ecológica do Seridó, Próximo à casa da entrada da ESEC, 11-IV2006, C.G.T. Ferreira \& V.A.O. Irmão 39 (MOSS); Próximo ao alojamento, 24-VI-2006, C.G.T. Ferreira \& G.S. Araújo 243 (MOSS).

Coletada com flores e frutos de abril a junho. Encontrada em locais arenosos antropizados, vertissolos, beira de estradas e locais areno-pedregosos.

\section{Agradecimentos}

Ao CNPq, pela concessão de bolsa PIBIC à primeira autora e bolsa de produtividade em pesquisa ao terceiro autor. Aos funcionários da ESEC: Adson Borges, George e "Irmão" por estimularem e facilitarem o trabalho. Ao Geraldo, mateiro e conhecedor da região, por seu auxílio como guia nas caminhadas e ajuda nas coletas. À Kátia Pinheiro, pelo auxílio com o trabalho no herbário. À Marcela Valls, pelas ilustrações.

\section{Literatura citada}

Amorim, I.L., Sampaio, E.V.S.B. \& Araújo, E.L. 2005. Flora e estrutura da vegetação arbustivo-arbórea de uma área de caatinga do Seridó, RN, Brasil. Acta Botanica Brasilica 19: 615-623.

Andrade-Lima, D. 1981. The caatingas dominium. Revista Brasileira de Botânica 4: 149-153.

Anton, A.M. 1980. The genus Tragus (Gramineae). Kew Bulletin 36: 55-61.

Araújo, E.L., Silva, K.A., Ferraz, E.M.N., Sampaio, E.V.S.\& Silva, S.I. 2005. Diversidade de herbáceas em microhabitats rochoso, plano e ciliar em uma área de caatinga, Caruaru, PE, Brasil. Acta Botanica Brasilica 19: 285-294.

Beetle, A.A., Forceck, E.M., Luque, V.J., Sánchez, P.G., Sánchez, A.M., Tancredi, I.N. \& Hernández, A.C. 1991. Las Gramineas de Mexico. Tomo II. Secretaria de Agricultura y Recursos Hidráulicos, México.

Beetle, A.A., Forceck, E.M., Sánchez, A.M., Luque, Hernández, A.C. \& Rodríguez, A.M.R. 1991. Las Gramineas de Mexico. Tomo III. Secretaria de Agricultura y Recursos Hidráulicos, México.

Boechat, C.B., Valls, J.F.M., Santos, A.M.P.V. \& Lima, V.S.L. 1993. As espécies do gênero Bouteloua Lag. (Gramineae, Chloridoideae) no Brasil. Iheringia, série Botânica 43: 41-66.

Boechat, C.B. \& Longhi-Wagner, H.M. 2001. O gênero Eragrostis (Poaceae) no Brasil. Iheringia, série Botânica 55: 23-169.

Boechat, S.C., Guglieri, A. \& Longhi-Wagner, H.M. 2001. Tribo Eragrostideae. In: M.G.L. Wanderley, G.J. Shepherd \& A.M. Giulietti (coords.). Flora Fanerogâmica do Estado de São Paulo. Hucitec, São Paulo, v. 1, pp. 61-84.

Boldrini, I.I. 2001. Echinochloa. In: M.G.L. Wanderley, G.J. Shepherd \& A.M. Giulietti (coords.). Flora Fanerogâmica do Estado de São Paulo. Hucitec, São Paulo, v. 1, pp. 150-152.

Camacho, R.G.V. \& Baptista, G.M.M. 2005. Análise geográfica computadorizada aplicada à vegetação da caatinga em unidades de conservação do Nordeste: a) Estação Ecológica do Seridó - ESEC/RN/Brasil. In: J.C.N. Epiphanio \& G.J.F. Banon (eds.). Anais do XII Simpósio Brasileiro de Sensoriamento Remoto, Goiânia. INPE, São José dos Campos, v. 1, pp. 2611-2618.

Canto-Dorow, T.S.2001.Digitaria.In: M.G.L. Wanderley, G.J. Shepherd \& A.M. Giulietti (coords.). Flora Fanerogâmica do Estado de São Paulo. Hucitec, São Paulo, v. 1, pp. 143-149.

Clayton, W.D. \& Renvoize,S.A. 1986. Genera Graminum - Grasses of de world. Kew Bulletin Additional Series 13: 1-389.

Costa-e-Silva, M.B. \& Maciel, J.R. 2007. Os gêneros Sporobolus e Leptochloa (Poaceae-Chloridoideae). Rodriguesia 58: 147-157.

Döll, J.C. 1877. Gramineae. In: C.F.P. Martius \& A.G. Eichler (eds.). Flora Brasiliensis. Lipsiae, Frid. Fleischer, v. 2, pars 2, pp. 1-342. 
Ekman, E.L. 1911. Neue brasilianische Gräser. Arkiv for Botanik 10: 1-43.

EMBRAPA. 1999. Sistema brasileiro de classificação de solos. Embrapa Produção de Informação, Brasília.

Filgueiras, T.S. 1989. Revisão de Mesosetum Steudel (Gramineae: Paniceae). Acta Amazonica 19: 47-114.

Filgueiras, T.S.\& Rodrigues-da-Silva, R. 2001. Cenchrus L. In: M.G.L. Wanderley, G.J. Shepherd \& A.M. Giulietti (coords.). Flora Fanerogâmica do Estado de São Paulo. Hucitec, São Paulo, v. 1, pp. 141-143.

Filgueiras, T.S. 2009 [continuously updated]. Heteropogon Pers.. In: R.J. Soreng, G. Davidse, P.M. Peterson, F.O. Zuloaga, E.F. Judziewicz, T.S. Filgueiras \& O. Morrone. Catologue of New World Grasses (Poaceae). Missouri Botanical Garden (http://mobot.mobot.org/W3T/ Search/nwgc.html (acesso em 15/06/2009).

Gould, F.W. 1968. Grass Systematics. McGraw-Hill. New York.

Guglieri, A., Longhi-Wagner, H.M. \& Zuloaga, F.O. 2006. Panicum L. subg. Panicum sect. Panicum (Poaceae) no Brasil. Hoehnea 33: 185-217.

Guglieri, A., Longhi-Wagner, H.M. \& Zuloaga, F.O. 2007. Panicum sect. Dichotomiflora (Hitchc. \& Chase) Honda e P. sect. Virgata Hitchc. \& Chase ex Pilg. (Poaceae: Panicoideae: Paniceae) no Brasil. Acta Botanica Brasilica 21: 785-805.

Hargreaves, G. H. 1974. Precipitation dependability and potentials for an agricultural production for Northeast Brazil. Utah State University, Logan.

Hilu, K.W. \& Alice, A.L. 2001. A phylogeny of Chloridoideae (Poaceae) based on matK sequences. Systematic Botany 26: 386-405.Hitchcock, A.S. 1936. Manual of the grasses of the West Indies. Miscellaneous publications 243. United States Department of Agriculture, Washington.

Holmgren, P.K., Holmgren, N.H. \& Barnett, L.C. 2005. Index Herbariorum, Part 1. The herbaria of the World. http://sci.web.nybg.org/science2/IndexHerbarioum.asp (acesso em 27.11.2005).

IBGE. 2004. Anuário Estatístico do Brasil. Instituto Brasileiro de Geografia e Estatística, Rio de Janeiro.

Longhi-Wagner, H.M. 1999. O gênero Aristida (Poaceae) no Brasil. Boletim do Instituto de Botânica 12: 113-179.

Longhi-Wagner, H.M. 2001b. Eriochloa Kunth. In: M.G.L. Wanderley, G.J. Shepherd \& A.M. Giulietti (coords.). Flora Fanerogâmica do Estado de São Paulo. Hucitec, São Paulo, v. 1, pp. 153-154.

MMA. 1998. Primeiro relatório nacional para a convenção sobre biodiversidade biológica - Brasil. Ministério do Meio Ambiente, Brasília.

Nascimento, M.P.S.B.\& Renvoize, S.A. 2001. Gramíneas forrageiras naturais e cultivadas na região Meio Norte. Embrapa Meio Norte, Teresina.

Oliveira, R.P., Longhi-Wagner, H.M. \& Giulietti, A.M. 2003. O gênero Ichnanthus (Poaceae: Paniceae) na Chapada Diamantina, Bahia, Brasil. Acta Botanica Brasilica 17: 49-70.
Parodi, L.R. 1969. Estudios sistemáticos sobre las Gramineae-Paniceae Argentina y Uruguayas. Darwiniana 15: 65-109.

Pensiero, J.F. 1999. Las espécies sudamericanas del gênero Setaria (Poaceae, Paniceae). Darwiniana 37: 37-151.

Peterson, P.M. \& Boechat, S.C. 2009. Eragrostis Wolf. In: R.J. Soreng, G. Davidse, P.M. Peterson, F.O. Zuloaga, E.F. Judziewicz, T.S. Filgueiras \& O. Morrone. Catologue of New World Grasses (Poaceae). Missouri Botanical Garden (http://mobot.mobot.org/W3T/ Search/nwgc.html (acesso em 15/06/2009).

Pohl, R.W. 1978. Family 15, Gramineae. In: W. Burger (ed.) Flora Costaricensis. Fieldiana Botany 4: 1-608.

Renvoize, S. A. 1984. The grasses of Bahia. Royal Botanical Garden, Kew.

Sampaio, E.V.S.B. 2003. Caracterização da caatinga e fatores ambientais que afetam a ecologia das plantas lenhosas. In: V.C. Sales (ed.). Ecossistemas brasileiros: manejo e conservação. Expressão Gráfica e Editora, Fortaleza, pp. 129-142.

Santana, J.A.S. \& Souto, J.S. 2006. Diversidade e estrutura fitossociológica da Caatinga na Estação Ecológica do Seridó-RN. Revista de Biologia e Ciências da Terra 6: 232-242.

Sulekic, A.A. \& Zapater, M.A. 2001. El gênero Tragus (Poaceae, Zoisieae) em la Argentina. Darwiniana 39: 247-254.

Tabarelli, M., Silva, J.M.C., Santos, A.M.M. \& Vicente, A. 2000. Análise de representatividade das unidades de conservação de uso direto e indireto na caatinga. In: J.M.C. Silva \& M. Tabarelli (coords.). Workshop avaliação e identificação de ações prioritárias para a conservação, utilização sustentável e repartição de benefícios da biodiversidade do bioma Caatinga. Petrolina, PE. www.biodiversitas.org.br/caatinga (acesso em 20.08.2007).

Tenório, E.C. 1968. Gramíneas do município de Recife. Boletim Técnico 36. Instituto de Pesquisas Agropecuárias, Recife.

Velloso, A.L., Sampaio, E.V.S.B. \& Pareyn, F.G.C. (eds.). 2002. Ecorregiões: Propostas para o bioma Caatinga. Associação Plantas do Nordeste, Instituto de Conservação Ambiental, The Nature Conservancy do Brasil, Recife.

Zanin, A. \& Longhi-Wagner, H.M. 2006. Sinopse do gênero Andropogon L. (Poaceae - Andropogoneae) no Brasil. Revista Brasileira de Botânica 29: 289-299.

Zizca, G. 1988. Revision der Melinidae Hitchcock (Poaceae, Panicoideae). Biblioteca botanica 138: 1-149.

Zuloaga, F.O. \& Morrone, O. 2003. Reimarochloa. In: R.J. Soreng \& S.J. Pennington (eds.). Catalogue of New World grasses (Poaceae): III. Subfamilies Panicoideae, Aristidoideae, Arundinoideae and Danthonioideae. Smithsonian Institution, Washington. Contributions from the United States National Herbarium 46: 543-544. 